Check for updates

Cite this: RSC Adv., 2019, 9, 34567

Received 15th July 2019

Accepted 10th September 2019

DOI: $10.1039 / c 9 r a 05415 d$

rsc.li/rsc-advances

\section{A facile and concise route to (hydroxybenzoyl) pyrido[2,3-d]pyrimidine heterocycle derivatives: synthesis, and structural, spectral and computational exploration $\dagger$}

\author{
Abida Ashraf, ${ }^{\text {ae }}$ Muhammad Khalid, (D) *b Muhammad Nawaz Tahir, ${ }^{c}$ \\ Muhammad Yaqub, ${ }^{a}$ Muhammad Moazzam Naseer, (D) d Ghulam Mustafa Kamal, ${ }^{b}$ \\ Bullo Saifullah, (D) br Ataualpa Albert Carmo Braga, (D) Zahid Shafiq ${ }^{\star a}$ \\ and Waqar Rauf $\mathbb{D}^{\mathrm{h}}$
}

In this work, we report the efficient synthesis of novel (hydroxybenzoyl)pyrido[2,3- $d$ ]pyrimidine heterocycle derivatives: 6-(2-hydroxy-5-methylbenzoyl)-1-methylpyrido[2,3-d]pyrimidine-2,4(1H,3H)-dione (6a), 6(5-fluoro-2-hydroxybenzoyl)-1-methylpyrido[2,3-d]pyrimidine-2,4(1H,3H)-dione $\quad(6 \mathrm{~b}), \quad 6$-(5-ethyl-2hydroxybenzoyl)-1-methylpyrido[2,3-d]pyrimidine-2,4(1H,3H)-dione $\quad(6 \mathrm{c}) \quad$ and 6-(2-hydroxy-5isopropylbenzoyl)-1-methylpyrido[2,3-d]pyrimidine-2,4(1H,3H)-dione $(6 \mathrm{~d})$. The chemical structures of the title compounds were ascertained by spectral techniques including ${ }^{1} \mathrm{H},{ }^{13} \mathrm{C} \mathrm{NMR}$, UV-visible and FTIR spectroscopy as well as single-crystal X-ray diffraction analysis. Additionally, density functional theory (DFT) and time-dependent (TD-DFT) computation were adopted to analyze the electronic structures of $6 a-d$. Compounds $6 a-d$ were computed in the ground state for FT-IR spectroscopic and natural bond orbital (NBO) analysis by DFT/B3LYP with the 6-311+G(d,p) basis set. UV-vis spectroscopic and HOMO and LUMO energy values for $6 a-d$ were determined via TD-DFT/B3LYP with the $6-311+G(d, p)$ basis set. The optimized geometric parameters, UV-vis findings, and vibrational frequencies indicate good consistency with the experimental data. NBO analysis was conducted to explore the interactions and charge transfer among different orbitals in the title compounds. The HOMO and LUMO band gap $(\Delta E)$ values for $6 \mathrm{a}-\mathrm{d}$ were found to be 3.93, 3.91, 4.10 and $3.91 \mathrm{eV}$, respectively. Molecular electrostatic potential (MEP) analysis explored the reactivity of the title compounds by predicting their nucleophilic as well as electrophilic sites. 
and analgesic, ${ }^{8}$ anticancer, ${ }^{9-11}$ antitumor, ${ }^{12,13}$ anti-diarrhea $3{ }^{14}$ calcium channel antagonist, and anti-leishmanial agents ${ }^{15}$ (Fig. 1).

Owing to their biological prominence, substantial effort has been focused towards synthetic strategies for pharmacologically active pyrido $[2,3-d]$ pyrimidines, though there remain many challenges for the synthesis of naturally occurring complex molecules. ${ }^{2}$

In continuation of our research work, ${ }^{16-20}$ we have synthesized some bioactive nitrogen- and oxygen-containing (hydroxybenzoyl)pyrido $[2,3-d]$ pyrimidine heterocycles. Quantum chemical approaches provided promising insights regarding the chemical and biological systems that often found good agreement with the experimental results. Nowadays, the term "quantum chemical approaches" is used almost synonymously with density functional theory (DFT). DFT calculations provide a reasonable compromise between cost and accuracy. Many scientific publications have revealed that the DFT findings have been in line with experiments. ${ }^{21}$ Moreover, DFT-based findings have been recognized as being better than the findings obtained from $a b$ initio methods. ${ }^{22}$ This might be one of the reasons behind the acceptance of DFT and it is extensively used in different fields of chemistry. Many DFT-based studies have addressed the various structural and mechanistic aspects of chemical systems. ${ }^{23}$ In this context, we performed DFT calculations for the molecular geometry to understand the structural parameters, vibrational spectroscopy, NBO analysis for intermolecular interactions and MEP for chemical reactivity surfaces, HOMO-LUMO and nonlinear optics (NLO) analysis for the electronic properties of (hydroxybenzoyl)pyrido[2,3- $d$ ] pyrimidine heterocycle derivatives.

\section{Experimental}

\section{Materials and methods}

IR spectra were recorded using a Bruker Alpha FT-IR spectrometer. Melting points were recorded using a Fisher-John melting point apparatus and were uncorrected. UV-visible spectra were recorded using a Shimadzu UV-1800. Proton NMR spectra were recorded using a Bruker (RheinstettenForchheim, Germany) AM $300 \mathrm{MHz}$ spectrometer and ${ }^{13} \mathrm{C}$ NMR spectra were recorded using a Bruker spectrometer at 75 $\mathrm{MHz}$ with TMS as the internal standard. Mass spectra were obtained using a Thermo Scientific LTQ-XL system with an electrospray ionization (ESI) source, a JEOL 600 MSRoute, and a JEOL Hx110 mass spectrometer (EI-HR).

\section{General procedure}

Synthesis of 6-(2-hydroxybenzoyl)-1-methylpyrido[2,3-d] pyrimidine-2,4(1H,3H)-dione (6a-d). A solution of substituted 3-formylchromone (2 mmol), 6-amino-1-methyluracil (2 mmol) and a catalytic amount of $p$-toluenesulfonic acid in $15 \mathrm{~mL}$ of THF was stirred under reflux for an appropriate time at $60{ }^{\circ} \mathrm{C}$. The completion of the reaction was examined by TLC. The yellow solid formed was filtered under hot conditions and washed with hot ethanol to afford the pure product (Scheme 1).

\section{Characterization}

6-(2-Hydroxy-5-methylbenzoyl)-1-methylpyrido[2,3-d]pyrimidine-2,4(1H,3H)-dione (6a). Light yellow; yield: 92\%; mp: 256$258{ }^{\circ} \mathrm{C} ;{ }^{1} \mathrm{H}$ NMR (DMSO- $d 6,300 \mathrm{MHz}$ ): $\delta=2.52\left(\mathrm{~s}, 3 \mathrm{H}, \mathrm{C}-\mathrm{CH}_{3}\right.$ ), $3.53\left(\mathrm{~s}, 3 \mathrm{H}, \mathrm{N}-\mathrm{CH}_{3}\right), 6.90\left(\mathrm{~d}, J=8.4 \mathrm{~Hz}, 1 \mathrm{H}\right.$, benzyl $\left.\mathrm{C}_{3}-\mathrm{H}\right), 7.21$ $(\mathrm{s}, 1 \mathrm{H}$, benzyl C $6-\mathrm{H}), 7.29\left(\mathrm{dd}, J=8.4 \mathrm{~Hz}, 2.1 \mathrm{~Hz}, 1 \mathrm{H}\right.$, benzyl $\mathrm{C}_{4}-$ $\mathrm{H}), 8.42\left(\mathrm{~d}, J=1.8 \mathrm{~Hz}, 1 \mathrm{H}\right.$, pyridyl $\left.\mathrm{C}_{5}-\mathrm{H}\right), 8.97(\mathrm{~d}, J=1.8 \mathrm{~Hz}, 1 \mathrm{H}$, pyridyl $\left.\mathrm{C}_{7}-\mathrm{H}\right), 10.13(\mathrm{~s}, 1 \mathrm{H}, \mathrm{OH}), 11.93(\mathrm{~s}, 1 \mathrm{H}, \mathrm{NH}) \mathrm{ppm} ;{ }^{13} \mathrm{C}$ NMR (DMSO- $d 6,75 \mathrm{MHz}) \delta=20.3,29.1,111.0,117.1,124.6$, 128.3, 128.7, 130.7, 134.9, 138.0, 151.0, 154.5, 154.6, 155.0, 161.4, $194.0 \mathrm{ppm}$; MS: $m / z$ 310.17 [M $-\mathrm{H}]^{-}$; anal. calcd for $\mathrm{C}_{16} \mathrm{H}_{13} \mathrm{~N}_{3} \mathrm{O}_{4}$ : C, 61.73; $\mathrm{H}, 4.21 ; \mathrm{N}, 13.50 \%$; found: $\mathrm{C}, 61.78 ; \mathrm{H}$, $4.24 ; \mathrm{N}, 13.48 \%$.

6-(5-Fluoro-2-hydroxybenzoyl)-1-methylpyrido[2,3- $d]$ pyrimidine-2,4(1H,3H)-dione (6b). Yellow; yield: $77 \%$; $\mathrm{mp} 214-216{ }^{\circ} \mathrm{C}$; ${ }^{1} \mathrm{H}$ NMR (DMSO-d6, $300 \mathrm{MHz}$ ): $\delta=3.53$ (s, 3H, N-CH ${ }_{3}$ ), 7.00 (dd,<smiles>Cc1cc(=O)n(C2CCCC2)c2nc(Nc3ccc(N4CCCCC4)cc3)ncc12</smiles><smiles>COc1cc(NCc2cnc3nc(N)nc(N)c3c2C)cc(OC)c1OC</smiles>

CDK-4 inhibitor<smiles>CN1CC2=C(NC3=C(C(=O)c4ccccc43)C2c2cccc(Br)c2)N(C)C1=O</smiles>

3
Inhibitor of dihydrofolate reductase
Anti-diarrhea

Fig. 1 Some drugs with a pyridopyrimidine skeleton. 
<smiles>[R]c1ccc2occ(C=O)c(=O)c2c1</smiles>

$4 a-d$
5<smiles>[R]c1ccc(O)c(C(=O)c2cnc3c(c2)c(=O)[nH]c(=O)n3C)c1</smiles>

$6 a-d$

Scheme 1 The synthesis of the pyrido[2,3-d]pyrimidine derivatives $6 a-d$.

$J=9.0 \mathrm{~Hz}, 4.5 \mathrm{~Hz}, 1 \mathrm{H}$, benzyl $\left.\mathrm{C}_{3}-\mathrm{H}\right), 7.24(\mathrm{dd}, J=8.7 \mathrm{~Hz}, 3.3 \mathrm{~Hz}$, $1 \mathrm{H}$, benzyl $\left.\mathrm{C}_{6}-\mathrm{H}\right), 7.33\left(\mathrm{td}, J=8.7 \mathrm{~Hz}, 3.3 \mathrm{~Hz}, 1 \mathrm{H}\right.$, benzyl $\left.\mathrm{C}_{4}-\mathrm{H}\right)$, $8.43\left(\mathrm{~d}, J=2.4 \mathrm{~Hz}, 1 \mathrm{H}\right.$, pyridyl $\left.\mathrm{C}_{5}-\mathrm{H}\right), 8.99(\mathrm{~d}, J=2.4 \mathrm{~Hz}, 1 \mathrm{H}$, pyridyl $\left.\mathrm{C}_{7}-\mathrm{H}\right), 10.26$ (s, 1H, OH), 11.95 (s, 1H, NH) ppm; MS: m/z $314.17[\mathrm{M}-\mathrm{H}]^{-}$; anal. calcd for $\mathrm{C}_{15} \mathrm{H}_{10} \mathrm{FN}_{3} \mathrm{O}_{4}$ : C, 57.15; $\mathrm{H}$, 3.20 ; N, 13.33\%; found: C, 57.20; H, 3.17; N, 13.29\%.

6-(5-Ethyl-2-hydroxybenzoyl)-1-methylpyrido[2,3-d]pyrimidine-2,4(1H,3H)-dione (6c). Yellow; yield: $88 \%$; mp: $270-$ $272{ }^{\circ} \mathrm{C} ;{ }^{1} \mathrm{H}$ NMR (DMSO- $d 6,300 \mathrm{MHz}$ ): $\delta=1.16(\mathrm{t}, J=7.8 \mathrm{~Hz}$, $3 \mathrm{H}$, ethyl $\mathrm{CH}_{3}$ ), 2.57 (q, $J=7.5 \mathrm{~Hz}, 2 \mathrm{H}$, benzyl $\mathrm{CH}_{2}$ ), 3.53 (s, $\left.3 \mathrm{H}, \mathrm{N}-\mathrm{CH}_{3}\right), 6.93\left(\mathrm{~d}, J=8.4 \mathrm{~Hz}, 1 \mathrm{H}\right.$, benzyl $\left.\mathrm{C}_{3}-\mathrm{H}\right), 7.24(\mathrm{~d}, J=$ $2.1 \mathrm{~Hz} 1 \mathrm{H}$, benzyl $\left.\mathrm{C}_{6}-\mathrm{H}\right), 7.33(\mathrm{dd}, J=8.4 \mathrm{~Hz}, 2.4 \mathrm{~Hz}, 1 \mathrm{H}$, benzyl $\left.\mathrm{C}_{4}-\mathrm{H}\right), 8.43\left(\mathrm{~d}, J=2.4 \mathrm{~Hz}, 1 \mathrm{H}\right.$, pyridyl $\left.\mathrm{C}_{5}-\mathrm{H}\right), 8.98(\mathrm{~d}, J$ $=2.1 \mathrm{~Hz}, 1 \mathrm{H}$, pyridyl $\left.\mathrm{C}_{7}-\mathrm{H}\right), 10.15(\mathrm{~s}, 1 \mathrm{H}, \mathrm{OH}), 11.92(\mathrm{~s}, 1 \mathrm{H}$, $\mathrm{NH}) ;{ }^{13} \mathrm{C}$ NMR (DMSO- $\left.d 6,75 \mathrm{MHz}\right) \delta=16.1,27.5,29.1,111.0$, 117.2, 124.6, 128.3, 129.6, 133.8, 135.2, 138.0, 151.0, 154.5, 154.8, 155.0, 161.4, 194.0 ppm; MS: $m / z 326.25[\mathrm{M}+\mathrm{H}]^{+}$; anal. calcd for $\mathrm{C}_{17} \mathrm{H}_{15} \mathrm{~N}_{3} \mathrm{O}_{4}: \mathrm{C}, 62.76 ; \mathrm{H}, 4.65 ; \mathrm{N}, 12.92 \%$; found: $\mathrm{C}$, $62.80 ; \mathrm{H}, 4.63 ; \mathrm{N}, 12.90 \%$.

6-(2-Hydroxy-5-isopropylbenzoyl)-1-methylpyrido[2,3-d] pyrimidine-2,4(1H,3H)-dione (6d). Orange red; yield: $89 \%$; mp 220-222 ${ }^{\circ} \mathrm{C} ;{ }^{1} \mathrm{H}$ NMR (DMSO- $\left.d 6,300 \mathrm{MHz}\right): \delta=1.19(\mathrm{~d}, J$ $=6.9 \mathrm{~Hz}, 6 \mathrm{H}$, isopropyl $\mathrm{CH}_{3}$ ), 2.57 (sept, $J=6.9 \mathrm{~Hz}, 1 \mathrm{H}$, benzyl $\mathrm{CH}), 3.53\left(\mathrm{~s}, 3 \mathrm{H}, \mathrm{N}-\mathrm{CH}_{3}\right), 6.94(\mathrm{~d}, J=8.4 \mathrm{~Hz}, 1 \mathrm{H}$, benzyl $\left.\mathrm{C}_{3}-\mathrm{H}\right), 7.26\left(\mathrm{~d}, J=2.1 \mathrm{~Hz} 1 \mathrm{H}\right.$, benzyl $\left.\mathrm{C}_{6}-\mathrm{H}\right), 7.33$ (dd, $J$ $=8.4 \mathrm{~Hz}, 2.4 \mathrm{~Hz}, 1 \mathrm{H}$, benzyl $\left.\mathrm{C}_{4}-\mathrm{H}\right), 8.43(\mathrm{~d}, J=2.4 \mathrm{~Hz}, 1 \mathrm{H}$, pyridyl $\left.\mathrm{C}_{5}-\mathrm{H}\right), 8.98\left(\mathrm{~d}, J=2.4 \mathrm{~Hz}, 1 \mathrm{H}\right.$, pyridyl $\left.\mathrm{C}_{7}-\mathrm{H}\right), 10.17(\mathrm{~s}$, $1 \mathrm{H}, \mathrm{OH}), 11.93(\mathrm{~s}, 1 \mathrm{H}, \mathrm{NH}) ;{ }^{13} \mathrm{C}$ NMR (DMSO-d6, $\left.75 \mathrm{MHz}\right) \delta=$ $24.4,29.1,32.9,111.0,117.2,124.5,126.0,128.2,128.3$, 128.5, 132.3, 138.1, 139.8, 151.0, 154.5, 154.9, 155.0, 161.4, $194.0 \mathrm{ppm}$; MS: $m / z$ 340.25 $[\mathrm{M}+\mathrm{H}]^{+}$; anal. calcd for $\mathrm{C}_{18} \mathrm{H}_{17} \mathrm{~N}_{3} \mathrm{O}_{4}$ : C, 63.71; $\mathrm{H}, 5.05 ; \mathrm{N}, 12.38 \%$; found: $\mathrm{C}, 63.66 ; \mathrm{H}$, $4.98 ; \mathrm{N}, 12.36 \%$.

\section{Computational procedures}

The Gaussian 09 program package ${ }^{24}$ was used for all the theoretical calculations by employing DFT. $^{25}$ The initial geometry was retrieved by using the single-crystal structures of compounds $\mathbf{6 a}-\mathbf{d}$. The geometry of $\mathbf{6 a - d}$ was optimized in the gas phase without following any symmetry restrictions by employing the B3LYP level of theory and the $6-311+G(d, p)$ basis set. Frequency analysis was used to confirm the ground state structures. No imaginary frequency was there in all cases. Hence, the stability of the optimized structures was ascertained by all the calculated vibrational frequencies. The B3LYP/6$311+\mathrm{G}(\mathrm{d}, \mathrm{p})$ level of theory was employed for frontier molecular orbitals (FMOs), NBO, FT-IR and NLO calculations. UV-vis spectra were computed by employing time-dependent density functional theory (TD-DFT) with the B3LYP level and the 6$311+\mathrm{G}(\mathrm{d}, \mathrm{p})$ basis set. GaussView 5.0 (ref. 26) was used to organize the input files. The molecular visualization programs Avogadro, ${ }^{27}$ Chem Craft $^{28}$ and Gaussview 5.0 were used to interpret the output file results.

\section{Results and discussion}

\section{Chemistry}

A series of substituted (2-hydroxybenzoyl)pyridopyrimidines, diverse heterocyclic compounds exhibiting biological importance, have been prepared by reacting substituted 3-formylchromone, 6-amino-1-methyluracil and a catalytic amount of $p$-toluenesulfonic acid in THF under reflux for an appropriate time at $60{ }^{\circ} \mathrm{C}$. The corresponding (2-hydroxybenzoyl)pyrido[2,3$d]$ pyrimidines were obtained as yellow-orange red solids in yields of $77-92 \%$. The reaction was started by the protonation of the formyl group with $p$-toluenesulfonic acid followed by the addition of 6-amino-1-methyluracil to obtain the targeted (2hydroxybenzoyl)pyridopyrimidine 6a. The structure of the synthesized compounds was established by spectroscopic data, i.e. FT-IR, ${ }^{1} \mathrm{H}$ and ${ }^{13} \mathrm{C}$ NMR. The FT-IR spectra of (2-hydroxybenzoyl)pyridopyrimidines $\mathbf{6 a - d}$ showed characteristic $\mathrm{OH}$ and $\mathrm{NH}$ stretching frequencies at $3212-3026 \mathrm{~cm}^{-1}$ and the $\mathrm{C}=\mathrm{O}$ stretching was observed in the $1721-1571 \mathrm{~cm}^{-1}$ region. The ${ }^{1} \mathrm{H}$ NMR spectra showed two separate singlets at 10.13-10.26 for $\mathrm{OH}$ and 11.92-11.95 for $\mathrm{NH}$ protons while $\mathrm{N}-\mathrm{CH}_{3}$ protons resonate at $3.52-3.53 \mathrm{ppm}$. The ${ }^{13} \mathrm{C}$ NMR data for compounds 
6a-d also support the IR and ${ }^{1} \mathrm{H}$ NMR data. The plausible mechanism of the reaction is outlined in Scheme S1.†

\section{Crystallographic data collection and structural refinement}

Crystals of compounds 6a-d suitable for X-ray analysis (Table 1) were obtained by slow evaporation of their solutions in THF and $\mathrm{MeOH}$ solvent under ambient conditions and were found to have a monoclinic crystal lattice with the $P 2_{1} / n$ space group, a monoclinic crystal lattice with the $P 2_{1} / c$ space group, a triclinic crystal lattice with the $P \overline{1}$ space group and a monoclinic crystal lattice with the $C 2 / c$ space group, respectively (Table 1 ).

The information regarding the type of diffractometer, absorption correction and $\mathrm{H}$-atom treatment can be seen in Table S17. $\dagger$ The molecular structures of 6-(2-hydroxybenzoyl)-1-methylpyrido[2,3- $d]$ pyrimidine-2,4-diones 6a-d along with the crystallographic numbering schemes are shown in Fig. 2. As shown in Fig. 2, the benzoyl moiety present at the 6-position of 1-methylpyrido $[2,3-d]$ pyrimidine-2,4-dione is tilted from the methylpyrido $[2,3-d]$ pyrimidine-2,4-dione plane in $\mathbf{6 a - d}$ with dihedral angles of $\mathrm{C}(6)-\mathrm{C}(8)-\mathrm{C}(9)-\mathrm{C}(13)=49.40(2)^{\circ}$ in $\mathbf{6 a}, \mathrm{C}(6)-\mathrm{C}(9)-\mathrm{C}(10)-\mathrm{C}(11)=$ $30.1(2)^{\circ}$ in $6 \mathbf{c}, \mathrm{C}(1)-\mathrm{C}(10)-\mathrm{C}(11)-\mathrm{C}(15)=-150.19(16)^{\circ}$ in $\mathbf{6 d}$ and $\mathrm{C}(6)-\mathrm{C}(7)-\mathrm{C}(8)-\mathrm{C}(12)=146.45(14)^{\circ}$ in $\mathbf{6 b}$. In all four compounds, the sigma bond on one side of the central carbonyl that is acting as a bridge between the phenyl and the 1-methylpyrido[2,3- $d]$ pyrimidine-2,4-dione rings has frozen rotation owing to the presence of strong intramolecular hydrogen bonds $[\mathrm{O}(1)-\mathrm{H}(1) \cdots$ $\mathrm{O}(2), 1.79(3) \AA$ in $6 \mathrm{a} ; \mathrm{O}(1)-\mathrm{H}(1) \cdots \mathrm{O}(2), 1.89 \AA$ in $6 \mathrm{c}$; $\mathrm{O}(1)-\mathrm{H}(1) \cdots$ $\mathrm{O}(2), 1.89 \AA$ in $6 \mathrm{~d}$; and $[\mathrm{O}(1)-\mathrm{H}(1) \cdots \mathrm{O}(2), 1.83 \AA$ in $\mathbf{6 b}]$, whereas the sigma bond on the other side can freely rotate. Owing to this rotation, the substituents present on the hydroxybenzoyl can adopt two arrangements, i.e. cis or trans to the methyl group present on the pyrido[2,3- $d]$ pyrimidine-2,4-dione. In both $\mathbf{6 a}$ and 6c where the substituents are methyl and ethyl, respectively, on the hydroxybenzoyl moiety, this arrangement is cis while it is trans in $\mathbf{6 d}$ and $\mathbf{6 b}$ where the substituents are isopropyl and fluorine, respectively, on the hydroxybenzoyl moiety.

An interesting feature of compounds $\mathbf{6 a - d}$ is their molecular packing in the solid state owing to the presence of various hydrogen bond donor and acceptor sites (Fig. 2 and 3). Interestingly, in compound $\mathbf{6 a}$ the amide moiety in pyrido[2,3- $d]$ pyrimidinedione interacts with the hydroxybenzyl moiety through hydrogen bonding $[\mathrm{N}(2)-\mathrm{H}(2 \mathrm{~A}) \cdots \mathrm{O}(2), 2.00 \AA$; $\mathrm{O}(1)-\mathrm{H}(1) \cdots \mathrm{O}(3)$, $2.42(2) \AA]$ providing a ten-membered ring rather than forming the centrosymmetric $R_{2}{ }^{2}(8)\{\cdots \mathrm{H}-\mathrm{N}-\mathrm{C}=\mathrm{O}\}_{2}$ synthon, resulting in 1D zig-zag supramolecular chains. However, this centrosymmetric $R_{2}{ }^{2}(8)\{\cdots \mathrm{H}-\mathrm{N}-\mathrm{C}=\mathrm{O}\}_{2}$ synthon is observed in both $6 \mathrm{c}[\mathrm{N}(2)-$ $\mathrm{H}(2 \mathrm{~A}) \cdots \mathrm{O}(3), 2.02 \AA]$ and $\mathbf{6 b}[\mathrm{N}(3)-\mathrm{H}(3 \mathrm{~A}) \cdots \mathrm{O}(4), 1.98 \AA]$. Interestingly, none of the arrangement observed in $\mathbf{6 a}, \mathbf{6 c}$ and $\mathbf{6 b}$ is present in the solid-state structure of $\mathbf{6 d}$, most probably owing to the presence of a bulky isopropyl group. The packing of compound $\mathbf{6 d}$ is mainly driven by $\mathrm{N}-\mathrm{H} \cdots \mathrm{O}[\mathrm{N}(2)-\mathrm{H}(2) \cdots \mathrm{O}(1), 2.16 \AA]$ and $\mathrm{C}-\mathrm{H} \cdots \mathrm{O}$ $[\mathrm{C}(6)-\mathrm{H}(6) \cdots \mathrm{O}(4), 2.496 \AA]$ hydrogen bonds (Fig. 4).

\section{Molecular geometry}

The structural parameters of $\mathbf{6 a - d}$ were calculated at the B3LYP level with the $6-311+G(d, p)$ basis set. The structural parameters resulting from DFT calculations were compared with the

Table 1 X-ray crystallographic data for $6 a-d$

\begin{tabular}{|c|c|c|c|c|}
\hline Crystal data & $6 \mathbf{a}$ & $6 \mathbf{b}$ & $6 c$ & 6d \\
\hline CCDC & 1909617 & 1909620 & 1909619 & 1909618 \\
\hline Chemical formula & $\mathrm{C}_{16} \mathrm{H}_{13} \mathrm{~N}_{3} \mathrm{O}_{4}$ & $\mathrm{C}_{15} \mathrm{H}_{10} \mathrm{FN}_{3} \mathrm{O}_{4}$ & $\mathrm{C}_{17} \mathrm{H}_{15} \mathrm{~N}_{3} \mathrm{O}_{4}$ & $\mathrm{C}_{18} \mathrm{H}_{17} \mathrm{~N}_{3} \mathrm{O}_{4}$ \\
\hline$M_{\mathrm{r}}$ & 311.29 & 315.26 & 325.32 & 339.34 \\
\hline Crystal system, space group & Monoclinic, $P 2_{1} / n$ & Monoclinic, $C 2 / c$ & Monoclinic, $P 2_{1} / c$ & Triclinic, $P \overline{1}$ \\
\hline Temperature (K) & 296 & 296 & 296 & 296 \\
\hline$a, b, c(\AA)$ & $\begin{array}{l}8.1712(11), 13.873(2), \\
12.3934(17)\end{array}$ & $\begin{array}{l}23.336(3), 6.9240(6), \\
17.2853(18)\end{array}$ & $\begin{array}{l}11.7250(5), 13.3565(6), \\
10.1992(4)\end{array}$ & $\begin{array}{l}8.4030(4), 9.6898(4) \\
10.9110(7)\end{array}$ \\
\hline$\alpha, \beta, \gamma\left(^{\circ}\right)$ & $92.098(6)$ & $108.798(3)$ & $114.332(2)$ & $\begin{array}{l}105.870(2), 98.586(2), \\
102.351(4)\end{array}$ \\
\hline$V\left(\AA^{3}\right)$ & $1403.9(3)$ & $2643.9(5)$ & $1455.37(11)$ & $814.10(7)$ \\
\hline$Z$ & 4 & 8 & 4 & 2 \\
\hline Radiation type & Mo K $\alpha$ & Mo K $\alpha$ & Mo K $\alpha$ & Mo K $\alpha$ \\
\hline$\mu\left(\mathrm{mm}^{-1}\right)$ & 0.11 & 0.13 & 0.11 & 0.10 \\
\hline Crystal size (mm) & $0.44 \times 0.30 \times 0.28$ & $0.44 \times 0.38 \times 0.30$ & $0.44 \times 0.38 \times 0.36$ & $0.41 \times 0.30 \times 0.27$ \\
\hline \multicolumn{5}{|l|}{ Data collection } \\
\hline$T_{\min }, T_{\max }$ & $0.940,0.980$ & $0.930,0.970$ & $0.930,0.975$ & $0.940,0.985$ \\
\hline $\begin{array}{l}\text { No. of measured, } \\
\text { independent and observed }[I \\
>2 \sigma(I)] \text { reflections }\end{array}$ & $9802,3315,2477$ & $8315,3120,2521$ & $8838,3413,2687$ & $8321,3154,2336$ \\
\hline$R_{\text {int }}$ & 0.057 & 0.031 & 0.035 & 0.032 \\
\hline$(\sin \theta / \lambda)_{\max }\left(\AA^{-1}\right)$ & 0.659 & 0.658 & 0.659 & 0.617 \\
\hline \multicolumn{5}{|l|}{ Refinement } \\
\hline$R\left[F^{2}>2 \sigma\left(F^{2}\right)\right], w R\left(F^{2}\right), S$ & $0.055,0.172,1.04$ & $0.043,0.123,1.04$ & $0.046,0.133,1.05$ & $0.048,0.156,1.04$ \\
\hline$\left.\Delta\rangle_{\max }, \Delta\right\rangle_{\min }\left(\mathrm{e}^{-3}\right)$ & $0.38,-0.28$ & $0.26,-0.19$ & $0.29,-0.20$ & $0.23,-0.23$ \\
\hline
\end{tabular}




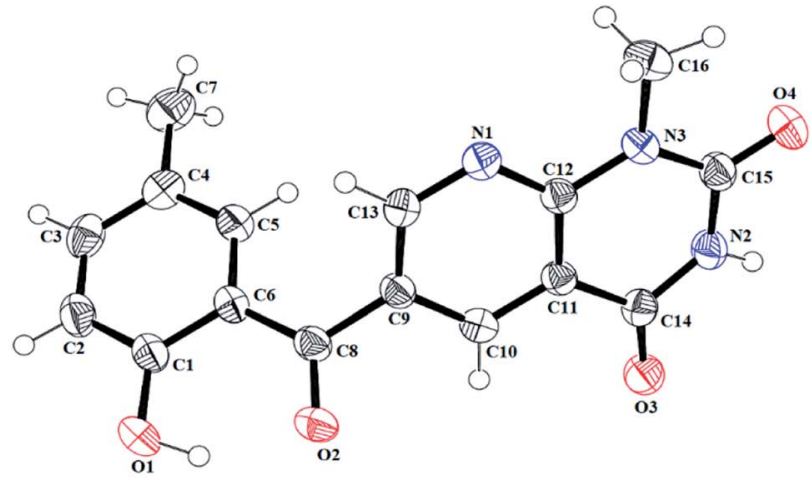

$6 \mathbf{a}$

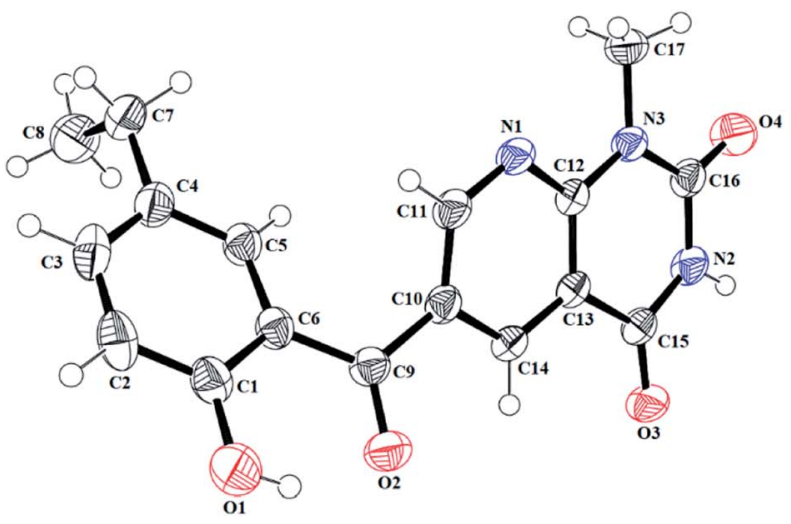

6c

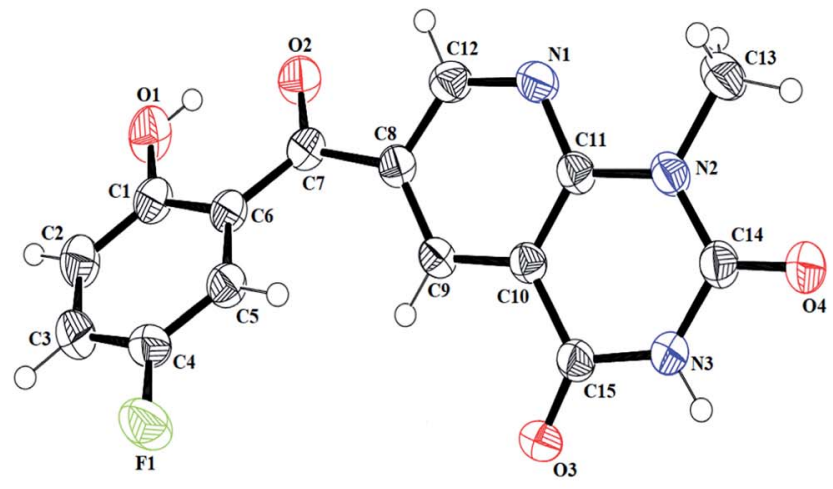

$\mathbf{6 b}$

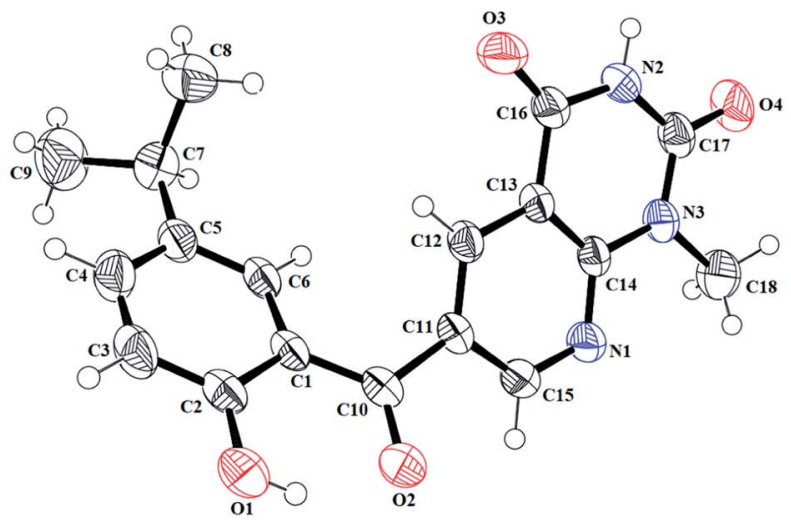

6d

Fig. 2 The molecular structures (ORTEP diagram) of 6-(2-hydroxybenzoyl)-1-methylpyridopyrimidine-2,4-diones 6a-d. Displacement ellipsoids are drawn at the $50 \%$ probability level.

subsequent crystal structural values obtained from XRD analysis. For 6a, the experimentally determined values for the N1C13, N2-C14, N2-C15, N3-C12, N3-C15 and N3-C16 bond lengths were 1.334(2), 1.372(2), 1.383(2), 1.385(2), 1.386(2) and 1.464(2) A, respectively. The DFT values for the aforementioned bond lengths were found to be 1.336, 1.332, 1.391, 1.393, 1.387, 1.395 and $1.470 \AA$, respectively. The experimentally determined values for the $\mathrm{O} 1-\mathrm{C} 1, \mathrm{O} 2-\mathrm{C} 8, \mathrm{O} 3-\mathrm{C} 14$ and $\mathrm{O} 4-\mathrm{C} 15$ bond lengths were 1.352(2), 1.235(2), 1.222(2), and 1.209(2) ̊, respectively, whereas, the DFT values were calculated to be 1.340, 1.239, 1.214 and $1.213 \AA$, respectively (Table S1 $\dagger$ ). The experimentally observed bond angles for O1-C1-C2, O2-C8-C9, O3-C14-N2, C12-N3-C15, O4-C15-N2 and C6-C8-C9 were 117.5(15), 117.2(14), 121.3(15), 122.0(14), 121.3(16) and 121.9(14) ${ }^{\circ}$, while the DFT values were found to be $117.8,122.9,121.7,118.0,121.2$ and $121.6^{\circ}$, respectively (Table S1 $\dagger$ ).

For $\mathbf{6 b}$, the experimentally determined values of the $\mathrm{C}-\mathrm{N}$ bond lengths for N1-C11, N1-C12, N2-C11, N2-C14 and N3C15 were 1.336(18), 1.324(19), 1.384(17), 1.367(19), and $1.378(18) \AA$ A, respectively. However, the DFT values of the C-N bond lengths were found to be 1.339, 1.327, 1.386, 1.396 and $1.390 \AA$ Å, respectively (Table S2†). Further, the experimentally determined values for the O1-C1, O2-C7, O3-C14 and O4-C14 bond lengths were 1.351(18), 1.242(16), 1.212(17) and 1.222(17) $\AA$, respectively, whereas the DFT values of these $\mathrm{C}-\mathrm{O}$ bond lengths were found to be $1.340,1.239,1.215$ and $1.212 \AA$, respectively (Table $\mathrm{S} 2 \dagger$ ). The experimentally determined bond angles values for F1-C4-C3, O2-C7-C6, O3-C15-N3, N1-C11N2, C13-N2-C14 and N3-C15-C10 were 118.2(13), 120.8(12), 121.2(12), 116.7(11), 117.8(12) and 113.9(11) ${ }^{\circ}$, while the DFT values for the same angles are 118.8, 120.7, 121.8, 116.8, 118.2 and $113.0^{\circ}$, respectively (Table S2 $\dagger$ ).

For $\mathbf{6 c}$, the experimentally determined values for the N1-C11, N1-C12, N2-C15, N2-C16, N3-C12, N3-C16 and N3-C17 bond lengths were 1.332(19), 1.336(17), 1.391(19), 1.393(19), 1.387(18), 1.395(18) and 1.470(18) ̊, respectively. The DFT values of the above-mentioned bond lengths were found to be $1.333,1.337,1.371,1.380,1.383,1.380$ and $1.468 \AA$, respectively. The experimentally determined values for the O1-C1, O2-C9, O3-C15 and O4-C16 bond lengths were 1.340(2), 1.239(18), 1.214(17) and 1.213(18) $\AA$, respectively. The DFT-based values of the above-mentioned bond lengths (C-O) were 1.349, 1.228, 1.220 and $1.210 \AA$, respectively (Table S3 $\dagger$ ). The experimentally determined bond angles observed for O1-C1-C2, O2-C9-C6, 

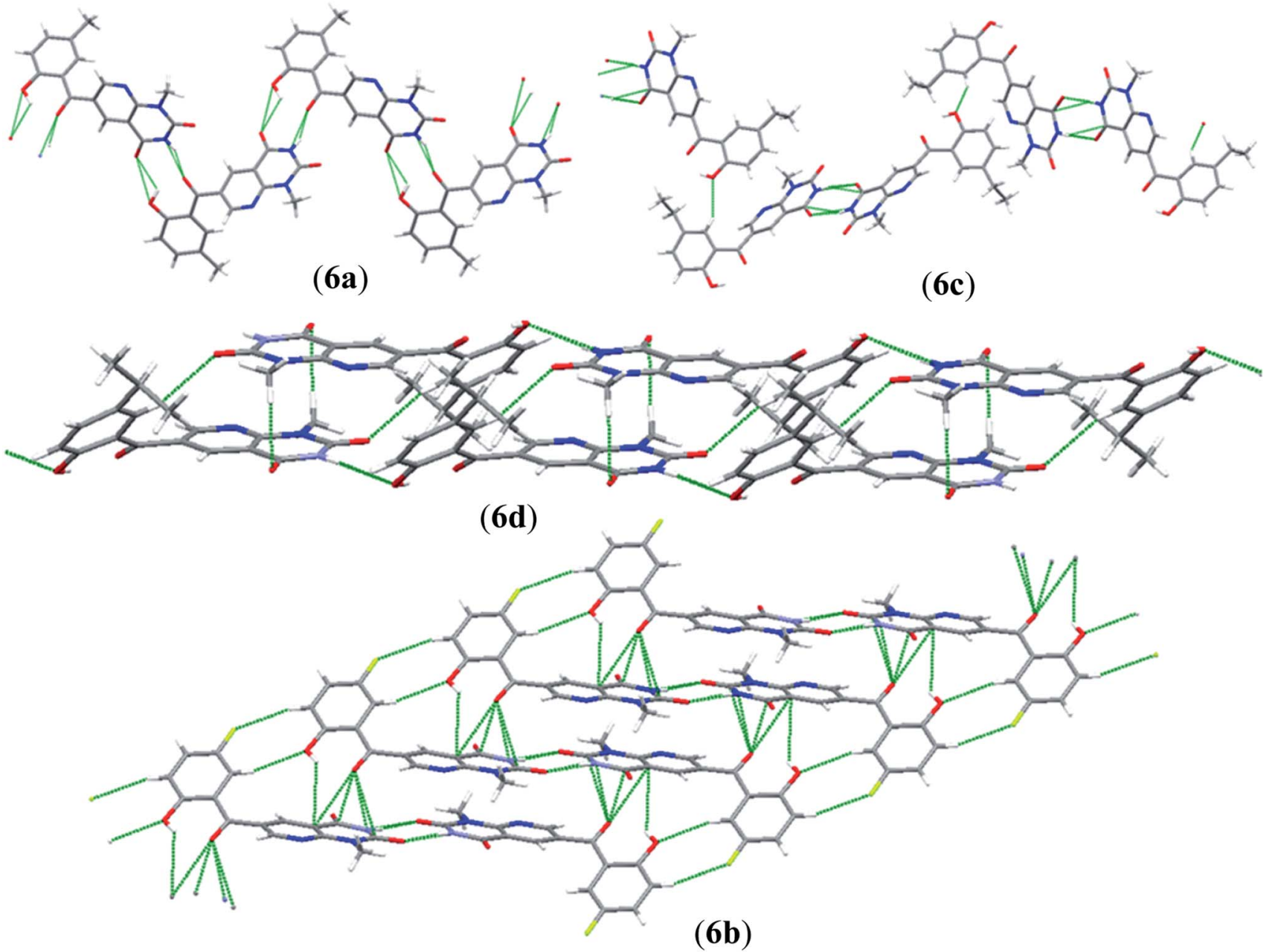

Fig. 3 The hydrogen bond-driven supramolecular chains in 6a-d.

O3-C15-C13, O4-C16-N3, N1-C11-C10, N2-C16-N3 and C3C4-C5 were 117.8(14), 121.1(13), 125.4(13), 123.6(14), 124.3(12), 115.2(13) and $117.5(14)^{\circ}$ while their DFT values were found to be $117.9,120.8,124.1,122.8,124.7,116.2$ and $117.1^{\circ}$, respectively (Table S3†).

Furthermore, for $\mathbf{6 d}$, the experimentally determined values of the N1-C14, N1-C15, N2-C16, N2-C17, N3-C14, N3-C17 and N3-C18 bond lengths were 1.332(2), 1.323(2), 1.368(2), 1.376(2), 1.384 (2), 1.377(2) and 1.462(2) ̊, respectively and the DFT values were $1.339,1.328,1.390,1.394,1.387,1.395$ and $1.471 \AA$, respectively (Table $\mathrm{S} 4 \dagger$ ). The experimentally obtained $\mathrm{C}-\mathrm{O}$ bond lengths for $\mathrm{O} 1-\mathrm{C} 2, \mathrm{O} 2-\mathrm{C} 10, \mathrm{O} 3-\mathrm{C} 16$ and $\mathrm{O} 4-\mathrm{C} 17$ were 1.352(2), 1.232(2), 1.210(2) and 1.205(2) $\AA$, respectively, while the DFT values were observed to be $1.341,1.240,1.215$ and $1.213 \AA$, respectively (Table $\mathrm{S} 4 \dagger$ ). The experimentally determined bond angles for O1-C2-C3, O2-C10-C1, O3-C16-N2, N1-C14-N3, $\mathrm{N} 1-\mathrm{C} 14-\mathrm{C} 13$ and $\mathrm{C} 2-\mathrm{C} 3-\mathrm{C} 4$ were 118.3(16), 121.6(16), 121.5(17), 116.7(15), 123.2(16) and $120.7(18)^{\circ}$ while the DFT values were $117.8,121.2,121.1,116.8,122.5$ and $120.5^{\circ}$, respectively. The comparative analysis reveals that the experimentally determined bond lengths and bond angles are slightly lower than the calculated parameters, as can be seen in Tables S1-S4. $\uparrow$ The observed difference between the DFT and experimental findings might be because of the medium effect. Overall, the obtained structural results for $\mathbf{6 a - d}$ from the DFT and XRD studies show good agreement, as can be seen in Tables S1$\mathrm{S} 4, \uparrow$ respectively.

\section{FT-IR analysis}

The experimental FT-IR absorption spectroscopic studies ${ }^{29,30}$ were performed for the vibrational modes of compounds 6a-d. Further, FT-IR absorption spectroscopic studies based on DFT analysis were also conducted to understand the vibrational modes of compounds 6a-d using the B3LYP/6-311+G(d,p) level of theory in the gas phase. The vibrational modes were assigned by employing the animation option available in GaussView software. Both the calculated and experimental frequencies are given in Tables S5-S8† for compounds $\mathbf{6 a - d}$, respectively.

$\mathbf{N}-\mathbf{H}$ vibrations. The wavenumbers for the nitrogenhydrogen $(\mathrm{N}-\mathrm{H})$ vibrations were located at 3092, 3119-3026, 3131-3045 and $3051 \mathrm{~cm}^{-1}$ for $\mathbf{6 a - d , ~ r e s p e c t i v e l y , ~ i n ~}$ 


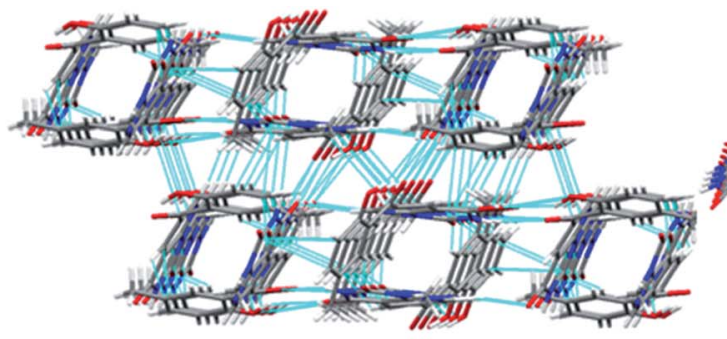

(a)

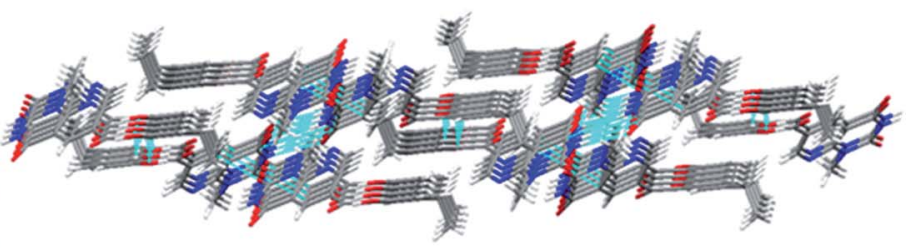

(b)

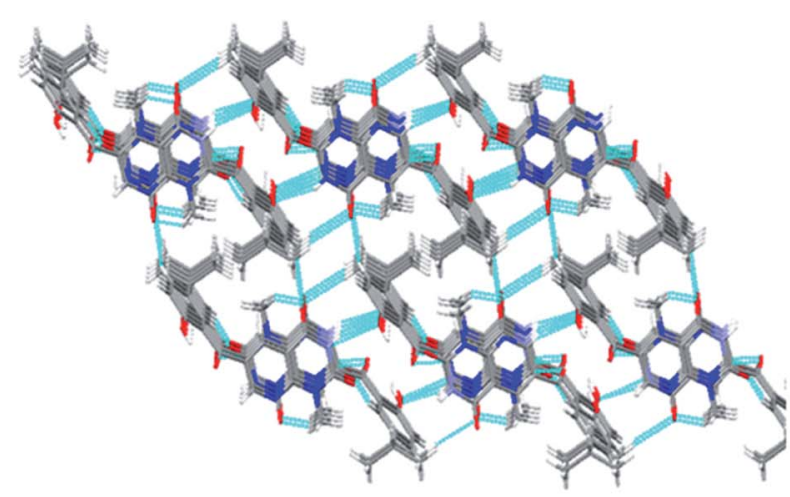

(c)

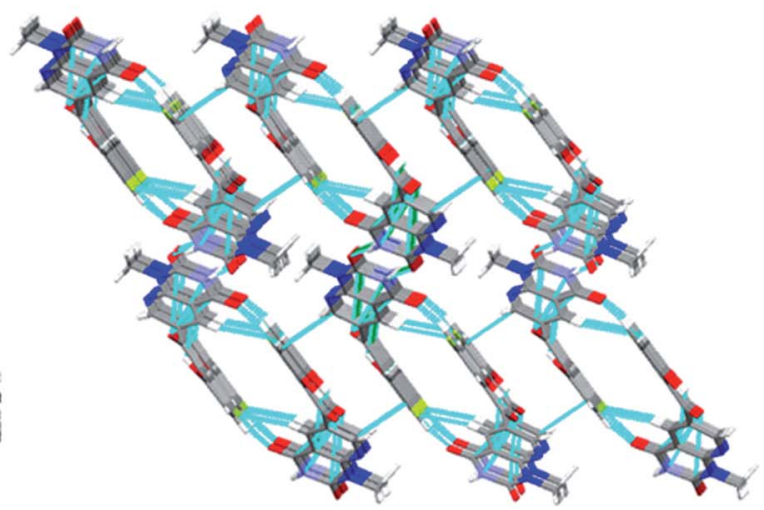

(d)

Fig. 4 3D packing of (a) 6 a along the $c$-axis; (b) $6 c$ along the $b$-axis; (c) $6 \mathrm{~d}$ along the $a$-axis; and (d) $6 \mathrm{~b}$ along the $b$-axis in the solid state.

experimental FT-IR spectrum which are in agreement with the calculated modes of 3594-3592 $\mathrm{cm}^{-1}$ (see Tables S5-S8†).

O-H vibrations. The experimentally determined wavenumbers for the hydroxy $(\mathrm{O}-\mathrm{H})$ groups were $3217,3163,3168$, and $3168 \mathrm{~cm}^{-1}$ for $\mathbf{6 a - d}$, respectively (Fig. S1-S4†); these lower frequencies might be due to intramolecular hydrogen bonding. The simulated bands of the former group were at 3382, 3395, 3385 , and $3391 \mathrm{~cm}^{-1}$ for $\mathbf{6 a}-\mathbf{d}$, respectively.

$\mathrm{C}=\mathbf{O}$ vibrations. A strong $\mathrm{C}=\mathrm{O}$ stretching vibration is found at $1850-1550 \mathrm{~cm}^{-1}$, which is a characteristic carbonyl group peak. $^{31}$ The carbonyl $(\mathrm{C}=\mathrm{O})$ group bands were located at 1717 1625, 1721-1589, $1685-1628$ and $1717-1571 \mathrm{~cm}^{-1}$ for $\mathbf{6 a - d}$, respectively (in the experimental spectra), and 1778-1629, 1780-1768, 1779-1770 and $1778-1632 \mathrm{~cm}^{-1}$ for 6a-d, respectively (in the DFT spectra). Good agreement was observed between the experimental and DFT-based wavenumbers (see Tables S5-S8†).

\section{Natural bond orbital (NBO) analysis}

NBO analysis is a significant method for examining intra- and inter-molecular bonding, especially in terms of conjugative and charge transfer interactions between the electron donor and acceptor. ${ }^{32-39} \mathrm{NBO}$ analysis is helpful in the transmission of electron density from a filled electron orbital to an unoccupied orbital. ${ }^{40}$ The stabilization energy can be calculated using eqn (1) with the second-order perturbation approach.

$$
E^{(2)}=q_{\mathrm{i}} \frac{\left(F_{\mathrm{i}, \mathrm{j}}\right)^{2}}{\varepsilon_{\mathrm{j}}-\varepsilon_{\mathrm{i}}}
$$

where $E^{(2)}$ is the stabilization energy, $q_{\mathrm{i}}$ is the donor orbital occupancy, $F_{(i, j)}$ is the diagonal and $\varepsilon_{\mathrm{j}}$ and $\varepsilon_{\mathrm{i}}$ are the off-diagonal NBO Fock matrix elements. ${ }^{41}$

The value of the perturbation stabilization energy $\left[E^{(2)}\right]$ depicts the level of conjugation in the whole system. The data for the NBO study regarding molecules $\mathbf{6 a - d}$ was obtained using the B3LYP/6-311+G(d,P) level of theory, as tabulated in Tables S9-S12. $\dagger$ The highest transitions $\left(\pi \rightarrow \pi^{*}\right)$ take place as $\pi$ (N6$\mathrm{C} 28) \rightarrow \pi^{*}(\mathrm{C} 24-\mathrm{C} 29)$ with $43.15 \mathrm{kcal} \mathrm{mol}^{-1}, \pi(\mathrm{C} 11-\mathrm{C} 19) \rightarrow$ $\pi^{*}(\mathrm{C} 12-\mathrm{C} 14)$ with $\mathrm{kcal} \mathrm{mol}^{-1}, \pi(\mathrm{C} 6-\mathrm{C} 30) \rightarrow \pi^{*}(\mathrm{C} 27-\mathrm{C} 28)$ with kcal $\mathrm{mol}^{-1}$ and $\pi(\mathrm{C} 10-\mathrm{C} 11) \rightarrow \pi^{*}(\mathrm{C} 12-\mathrm{C} 14)$ with $170.92 \mathrm{kcal} \mathrm{mol}^{-1}$ for $\mathbf{6 a - d}$, respectively. These are the largest values among the stabilization energies given in Tables S9S12. $\uparrow$ The stabilization energy value of $\mathbf{6 b}$ is higher than those for the other compounds $\mathbf{6 a}, \mathbf{6 c}$ and $\mathbf{6 d}$ owing to the stronger intramolecular hyper conjugative interactions, which might be due to the fluoro group. Transitions $\sigma(\mathrm{O} 1-\mathrm{H} 2) \rightarrow \sigma^{*}(\mathrm{C} 10-\mathrm{C} 12)$, $\sigma(\mathrm{O} 5-\mathrm{C} 33) \rightarrow \sigma^{*}(\mathrm{C} 24-\mathrm{C} 33), \sigma(\mathrm{C} 36-\mathrm{H} 39) \rightarrow \sigma^{*}(\mathrm{C} 36-\mathrm{H} 39)$ and $\sigma(\mathrm{C} 39-\mathrm{H} 42) \rightarrow \sigma^{*}(\mathrm{C} 39-\mathrm{H} 42)$ shown stabilization energy values of $6.07,65.09,53.30$ and $51.83 \mathrm{kcal} \mathrm{mol}^{-1}$ for $\mathbf{6 a - d}$, respectively. These are the highest $\sigma \rightarrow \sigma^{*}$ stabilization energies in the studied compounds, which result in a strong interaction between the donor $(\sigma)$ and the acceptor $\left(\sigma^{*}\right)$. In the case of the resonance, the transitions $\mathrm{LP}(\mathrm{N} 9) \rightarrow \sigma^{*}(\mathrm{O} 5-\mathrm{C} 32), \mathrm{LP}(\mathrm{N} 9) \rightarrow$ $\pi^{*}(\mathrm{C} 35-\mathrm{C} 37), \mathrm{LP}(\mathrm{N} 9) \rightarrow \sigma^{*}(\mathrm{C} 35-\mathrm{C} 37)$ and $\mathrm{LP}(\mathrm{N} 7) \rightarrow \pi^{*}(\mathrm{O} 4-$ C37) exhibit stabilization energy values of 70.30, 51.05, 78.19 and $52.43 \mathrm{kcal} \mathrm{mol}^{-1}$ for $\mathbf{6 a - d}$, respectively, as the largest energy values (see Tables S9-S12†). The lowest values of 5.53, 5.88, 5.45 and $7.05 \mathrm{kcal} \mathrm{mol}^{-1}$ were exhibited by $\mathrm{LP}(\mathrm{N} 6) \rightarrow \sigma^{*}(\mathrm{~N} 9-\mathrm{C} 28)$, $\mathrm{LP}(\mathrm{F} 1) \rightarrow \sigma^{*}(\mathrm{C} 16-\mathrm{C} 17), \mathrm{LP}(\mathrm{N} 6) \rightarrow \sigma^{*}(\mathrm{~N} 9-\mathrm{C} 30)$ and $\mathrm{LP}(\mathrm{N} 9) \rightarrow$ 
$\sigma^{*}(\mathrm{C} 39-\mathrm{C} 40)$ in $\mathbf{6 a - d}$, respectively (see Tables S9-S12 $\dagger$ ). Subsequently, on the basis of the NBO analysis, it can be concluded that the increased stability in these systems (6a-d) is mainly contributed by strong intramolecular hyper conjugative interactions.

\section{Frontier molecular orbital analysis}

In order to gain an understanding of the optical properties shown by these compounds, TD-DFT calculations for $\mathbf{6 a - d}$ were carried out at the TD-B3LYP/6-311G+(d,p) level after optimization of their molecular structures for stable spatial conformation. It was realized from SC-XRD findings that the molecular structure of the benzoyl moiety present at position 6 of 1methylpyridopyrimidine-2,4-dione is tilted from the methylpyridopyrimidine-2,4-dione plane in 6a-d with the dihedral angles $\mathrm{C}(6)-\mathrm{C}(8)-\mathrm{C}(9)-\mathrm{C}(13)=49.40^{\circ}$ in $\mathbf{6 a}, \mathrm{C}(1)-$ $\mathrm{C}(10)-\mathrm{C}(11)-\mathrm{C}(15)=-150.17^{\circ}$ in $6 \mathbf{b}, \mathrm{C}(6)-\mathrm{C}(9)-\mathrm{C}(10)-\mathrm{C}(11)=$ $30.11^{\circ}$ in $\mathbf{6 c}$, and $\mathrm{C}(6)-\mathrm{C}(7)-\mathrm{C}(8)-\mathrm{C}(12)=146.45^{\circ}$ in $\mathbf{6 d}$, which provides some obstruction for the intramolecular charge transfer (ICT) process within 6a-d. The TD-DFT calculations anticipated that the $\mathrm{S} 0 \rightarrow \mathrm{S} 1$ transitions are governed through a one-electron transformation from the HOMO to the LUMO. Additionally, according to the TD-B3LYP calculations, the preeminent contributions for the frontier molecular orbitals (FMOs) to the leading transitions in the investigated compounds are shown in Table S13. $\uparrow$ The major contribution of the molecular orbitals to the leading transitions is HOMO $\rightarrow$ LUMO+1 (99\%) and HOMO $\rightarrow$ LUMO (97\%) for 6a. Similarly, the major contribution of the molecular orbitals to the leading transitions is HOMO $\rightarrow$ LUMO+1 (98\%) and HOMO $\rightarrow$ LUMO (97\%) for $6 \mathbf{b}$. Moreover, the major contribution of the molecular orbitals to the leading transitions is HOMO $\rightarrow$ LUMO+1 (99\%) and HOMO $\rightarrow$ LUMO (97\%) for 6c and HOMO $\rightarrow$ LUMO+1 $(98 \%)$ and HOMO $\rightarrow$ LUMO (96\%) for $\mathbf{6 d}$ (see Table S13 $\dagger$ ). The FMO diagrams can be seen in Fig. 5-8, which show the electron distribution of the HOMO-2, HOMO-1 and HOMO as well as the LUMO, LUMO+1 and LUMO+2 of molecules $6 \mathbf{a}-\mathbf{d}$. We can see that the electron distribution of the HOMOs of compound 6a is mainly dispersed over methyl benzoyl moiety, while the LUMO electron distribution is mainly localized over the compound with the exception of the methyl group of the benzoyl moiety and the pyridopyrimidine-2,4-dione moiety (Fig. 5).

For $\mathbf{6 b}$, the electron distribution of the HOMOs is also mainly dispersed over methyl benzoyl moiety, while the LUMO electron distribution is mainly localized over the whole compound with the exception of the methyl group and the $\mathrm{C}-\mathrm{N}$ bond of the pyridopyrimidine-2,4-dione moiety as well as only a bit extended on the carbonyl functional group of the pyridopyrimidine-2,4-dione moiety (see Fig. 6).

For $6 \mathbf{c}$, the electron distribution of the HOMOs is mainly dispersed over the pyridopyrimidine-2,4-dione moiety, while the LUMO electron distribution is are mainly localized on over the pyridopyrimidine-2,4-dione moiety as well as only a bit extended on the carbonyl functional group of the benzoyl moiety (see Fig. 7).

Further, for $\mathbf{6 d}$, the electron distribution of the HOMOs is mainly dispersed over the methyl benzoyl moiety, while the LUMO electron distribution is mainly localized over the compound with the exception of the methyl group of the benzoyl moiety (see Fig. 8).

Subsequently, this mechanism reveals the existence of ICT character from HOMO to LUMO orbitals.

In addition, the calculated energy values for the HOMOLUMO and energy gap ( $\left.E_{\text {gap }}\right)$ for these compounds are tabulated in Table 2. Subsequently, the energy band gaps $\left(E_{\text {gap }}\right)$ of the HOMO-LUMO levels for compounds 6a-d are $3.93 \mathrm{eV}, 3.91 \mathrm{eV}$, $4.1 \mathrm{eV}$ and $3.91 \mathrm{eV}$, respectively.

The energy gaps of the studied compounds decrease in the following order:

$$
6 c>6 a>6 b=6 d
$$

The computing calculations show that the electronic properties of the four derivatives might be affected through by the electron donating capability of the substituents, which might

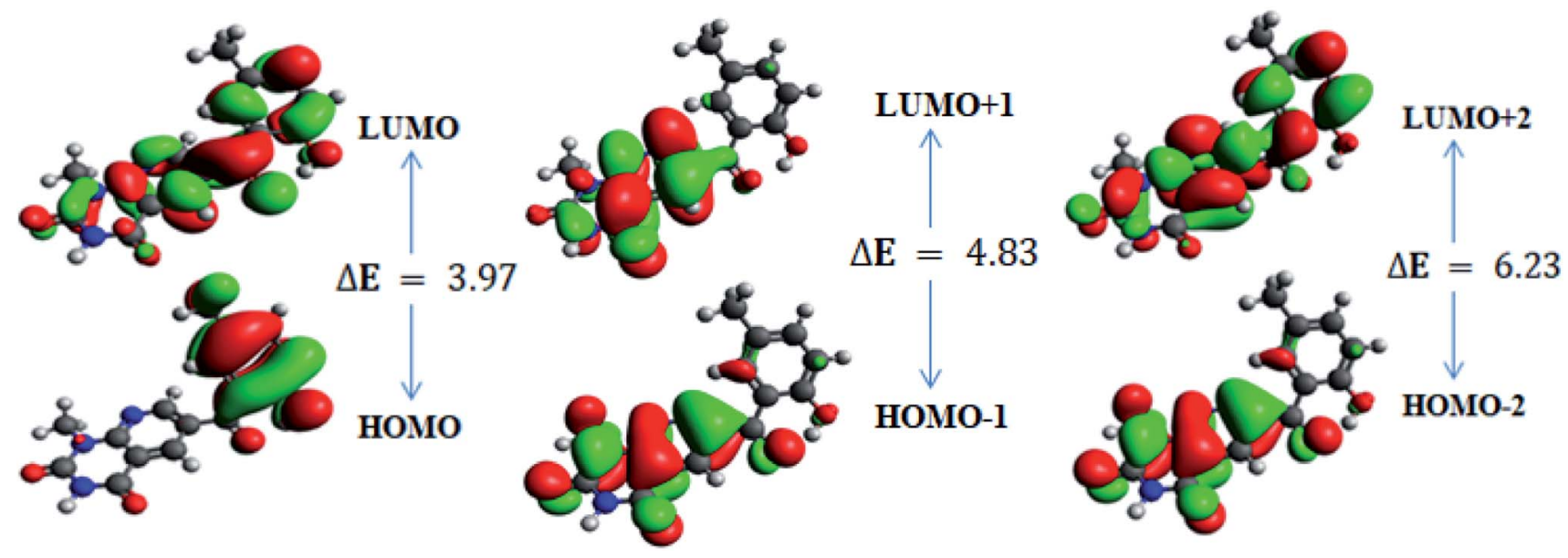

Fig. 5 Frontier molecular orbitals of $6 a$. 


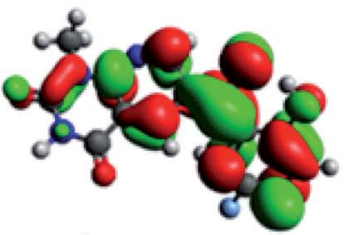

LUMO

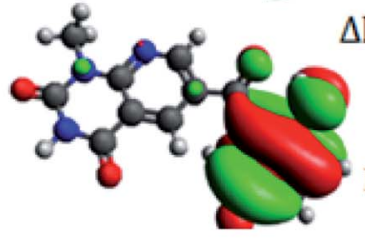

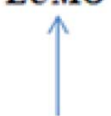

$\Delta \mathbf{E}=3.91$

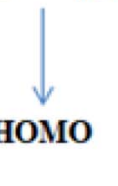

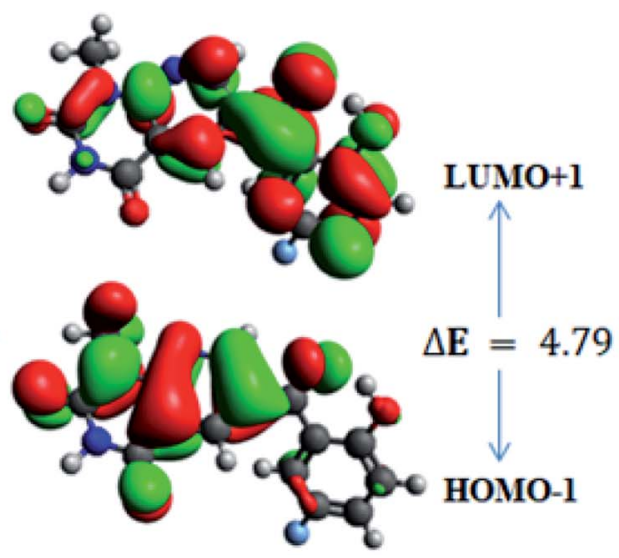

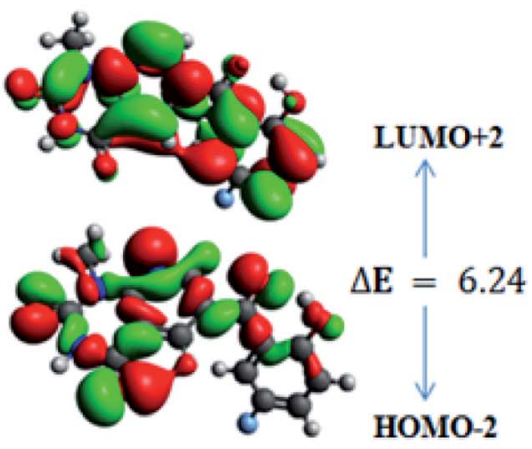

Fig. 6 Frontier molecular orbitals of $6 b$.

effectively tune their optical characteristics and the lower $E_{\text {gap }}$ explains that the aforesaid derivatives would contain strong electron transfer ability and larger second-order NLO properties. ${ }^{42,43}$

Moreover, the calculated energy values for the FMOs are used for calculating the values of the global reactivity descriptors. ${ }^{44-47}$

The electronic affinity $(A)$ and ionization potential $(I)$ have been calculated in a vertical manner using eqn (2) and (3).

$$
\begin{gathered}
I=E_{\mathrm{c}}{ }^{N-1}-E_{\mathrm{o}}{ }^{N} \\
A=E_{\mathrm{o}}{ }^{N}-E_{\mathrm{A}}{ }^{N+1}
\end{gathered}
$$

where $I=$ ionization potential; $A=$ electron affinity; $E_{\mathrm{c}}{ }^{N-1}=$ cation (energy after losing one electron); ${E_{\mathrm{o}}}^{N}=$ basal state energy (neutral); and $E_{\mathrm{A}}{ }^{N+1}=$ anion (energy after gaining one electron).

Hardness and electronegativity values have been calculated using eqn (4) and (5).

$$
\begin{aligned}
& \eta=\frac{I-A}{2} \\
& X=\frac{I+A}{2}
\end{aligned}
$$

Electrophilicity calculations were performed to establish the charge transfer process. This describes the relationship between energy variation and the maximum electrons transferred.

$$
\omega=\frac{\mu^{2}}{2 \eta}
$$

The ability of a chemical species to donate or accept an electron can be explained with the help of two descriptors. eqn (7) and (8) were used to calculate the donating and accepting ability of $\mathbf{6 a - d}$, respectively.

$$
\begin{aligned}
& \omega^{-}=\frac{(3 I+A)^{2}}{16(I-A)} \\
& \omega^{+}=\frac{(I+3 A)^{2}}{16(I-A)}
\end{aligned}
$$

where, $\omega^{-}=$electron donating capability; and $\omega^{+}=$electron accepting capability.

Eqn (9) was used to calculate the softness value.

$$
\sigma=\frac{1}{2 \eta}
$$
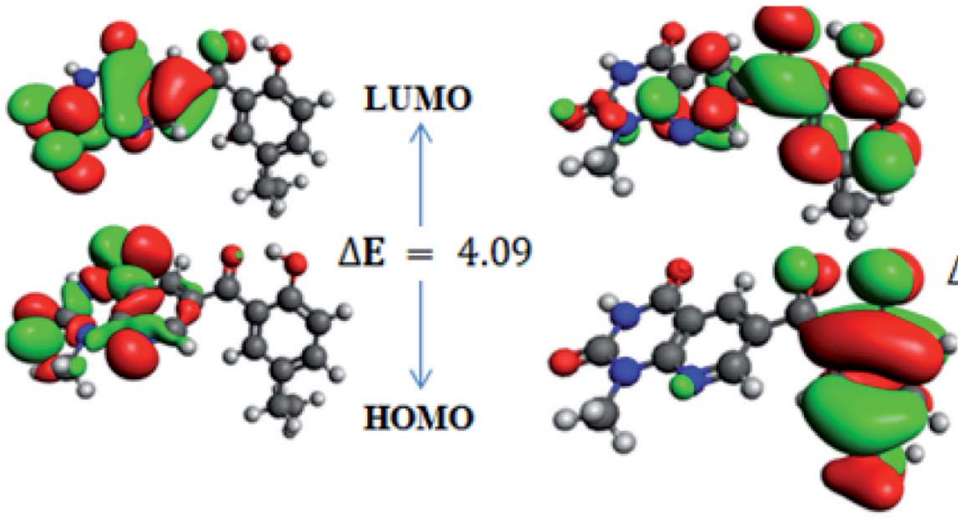

LUMO+1

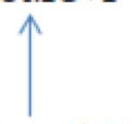

$\Delta \mathbf{E}=5.09$
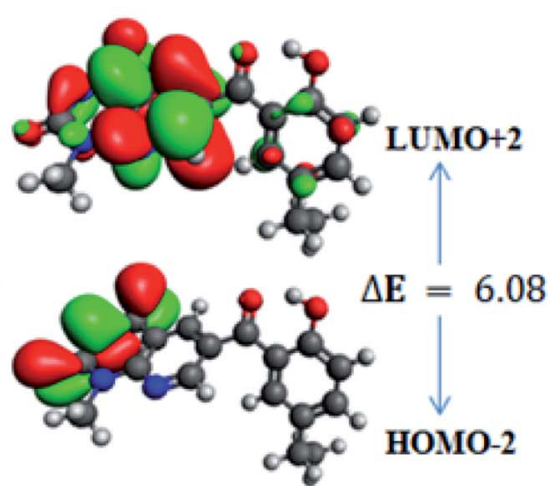

Fig. 7 Frontier molecular orbitals of $6 c$. 

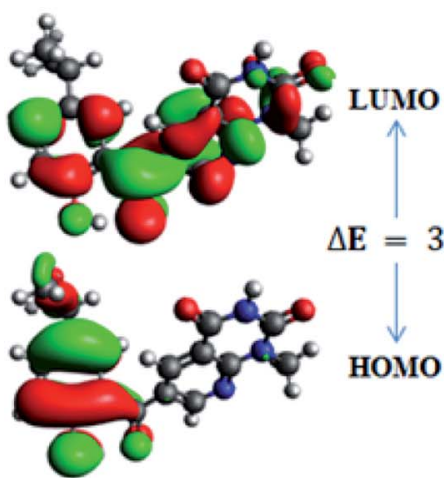

$\Delta \mathbf{E}=3.91$
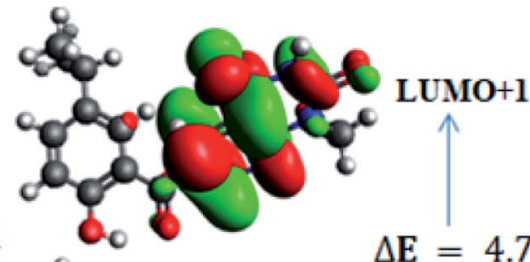

$\Delta \mathrm{E}=4.79$
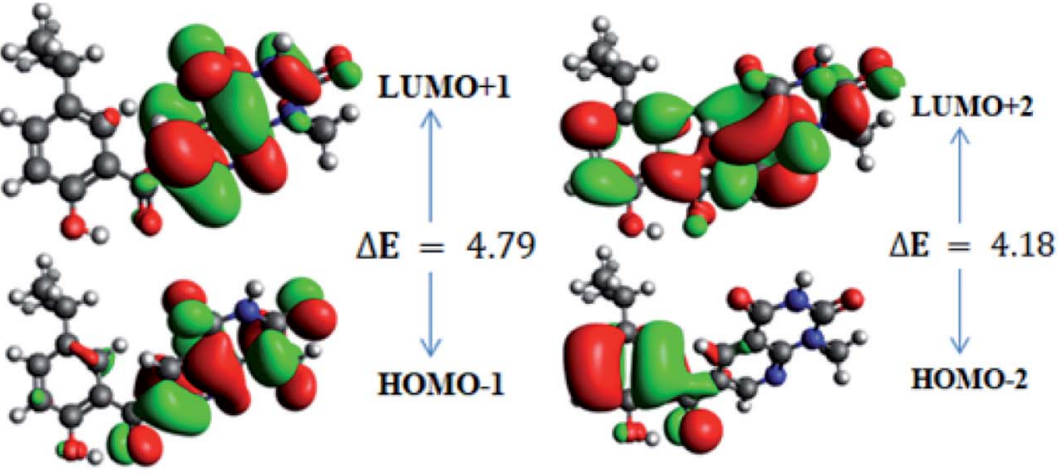

Fig. 8 Frontier molecular orbitals of $6 \mathrm{~d}$.

The results obtained from eqn (2)-(9) are summarized in Table 3.

The highest ionization potential was calculated to be $5.46 \mathrm{eV}$ for $\mathbf{6 b}$, while the lowest ionization potential was observed for $\mathbf{6 a}$ with a value of $5.19 \mathrm{eV}$. The ionization potential decreases in the following order: $\mathbf{6 b}>\mathbf{6 c}>\mathbf{6 d}>\mathbf{6 a}$. The highest electron affinity value was found to be $4.63 \mathrm{eV}$ for $\mathbf{6 b}$, while the other three derivatives have the same electron affinity of $1.43 \mathrm{eV}$. The ionization potential and electron affinity can be used to describe the electron releasing and accepting capabilities of the investigated molecules, which are directly related to the energy of the HOMOs and LUMOs. Overall, the ionization potential values are observed to be larger than the electron affinity values, highlighting the better electron donating capability of the investigated molecules (6a-d). Usually, a molecule with a high energy gap can be considered as a hard, non-reactive, stable species, and vice versa. The global hardness values of our studied systems were found to descend in the following order; $\mathbf{6 b}>\mathbf{6} \mathbf{c}>\mathbf{6 d}>\mathbf{6 a}$ (Table 3). A similar trend is observed for the electronegativity values of the studied compounds (6a-d) (Table $3)$. The chemical potential value of any system can be used to describe its reactivity and stability. Molecules with greater chemical potential values could be considered as less reactive and more stable, and vice versa. In decreasing order, the chemical potential values for the studied compounds are: [ $6 \mathbf{b}(\mu$ $=-5.04 \mathrm{eV})]>[6 \mathbf{c}(\mu=-4.81 \mathrm{eV})]>[6 \mathbf{d}(\mu=-4.78 \mathrm{eV})]>[6 \mathbf{a}(\mu=$ $-4.62 \mathrm{eV})]$.
The global softness values were found to be 2.69, 1.21, 1.30 and $1.41 \mathrm{eV}$ for $\mathbf{6 a - d}$, respectively. These values have a greater magnitude as compared to their global hardness values. The global electrophilicity $(\omega)$ decreases in the following order: $6 \mathbf{a}$ $(57.42 \mathrm{eV})>\mathbf{6 d}(32.16 \mathrm{eV})>\mathbf{6 b}(30.79 \mathrm{eV})>\mathbf{6 c}(30.09 \mathrm{eV}) . \mathrm{In}$ decreasing order, the electron donor capability $\left(\omega^{-}\right)$values are: $\mathbf{6 a}(59.75 \mathrm{eV})>\mathbf{6 d}(34.59 \mathrm{eV})>\mathbf{6 b}(33.36 \mathrm{eV})>\mathbf{6 c}(32.55 \mathrm{eV})$ and the electron acceptor capability $\left(\omega^{+}\right)$values are: $6 \mathbf{a}(55.13 \mathrm{eV})>$ 6d $(29.81 \mathrm{eV})>\mathbf{6 b}(28.32 \mathrm{eV})>\mathbf{6 c}(27.73 \mathrm{eV})$.

Overall, the electron donating capability $\left(\omega^{-}\right)$values were found to be higher than the electron accepting $\left(\omega^{+}\right)$capability values. The ionization energy and electron affinity values represent the ability of an atom to donate and accept electrons, respectively. In our compounds, the ionization energies were much higher than the electron affinity values, which supports the finding that the electron donating ability $\left(\omega^{-}\right)$of the investigated compounds is higher than their electron accepting ability $\left(\omega^{+}\right)$. The aforementioned results show that all investigated molecules have good kinetic stability and electron donating capability.

\section{UV-visible study}

The UV-vis absorption spectra of the derivatives (6a-d) in acetone, dimethyl sulfoxide (DMSO) and 1, 4-dioxane were recorded at room temperature. DT-DFT UV-vis absorption data were calculated in the gas phase. The UV-visible results for $\mathbf{6 a -}$ d are presented in Table 4 .

Table 2 Computed energies $(E)$ for compounds $6 a-d^{a}$

\begin{tabular}{|c|c|c|c|c|c|c|c|c|c|c|c|}
\hline \multicolumn{3}{|l|}{$6 a$} & \multicolumn{3}{|l|}{$6 \mathbf{b}$} & \multicolumn{3}{|l|}{$6 \mathrm{c}$} & \multicolumn{3}{|l|}{ 6d } \\
\hline MO & Energy & $\Delta E$ & MO & Energy & $\Delta E$ & MO & Energy & $\Delta E$ & MO & Energy & $\Delta E$ \\
\hline LUMO & -2.6 & & LUMO & -2.9 & & LUMO & -6.5 & & LUMO & -2.6 & \\
\hline HOMO-1 & -7.2 & 4.8 & HOMO-1 & -7.3 & 4.7 & HOMO-1 & -10.7 & 5.10 & HOMO-1 & -7.2 & 4.78 \\
\hline LUMO+1 & -2.4 & & LUMO+1 & -2.5 & & LUMO+1 & -5.6 & & LUMO+1 & -2.4 & \\
\hline
\end{tabular}

${ }^{a} E=$ energy; $\Delta E(\mathrm{eV})=E_{\mathrm{LUMO}}-E_{\mathrm{HOMO}} ; \mathrm{HOMO}$, highest occupied molecular orbital; LUMO, lowest unoccupied molecular orbital; MO, molecular orbital. 
Table 3 Ionization potential $(I)$, electron affinity $(A)$, electronegativity $(X)$, global hardness $(\eta)$, chemical potential $(\mu)$, global electrophilicity $(\omega)$, electron donor capability $\left(\omega^{-}\right)$, electron acceptor capability $\left(\omega^{+}\right)$ and global softness $(\sigma)$ values of $6 a-d$ (units in $\mathrm{eV}$ )

\begin{tabular}{llllllllll}
\hline Com & $I$ & $A$ & $X$ & $\eta$ & $\mu$ & $\omega$ & $\omega^{-}$ & $\omega^{+}$ & $\sigma$ \\
\hline 6a & 4.80 & 4.43 & 4.62 & 0.18 & -4.62 & 57.42 & 59.75 & 55.13 & 2.69 \\
6b & 5.46 & 4.63 & 5.04 & 0.41 & -5.04 & 30.79 & 33.36 & 28.32 & 1.21 \\
6c & 5.20 & 4.43 & 4.81 & 0.38 & -4.81 & 30.09 & 32.55 & 27.73 & 1.30 \\
6d & 5.14 & 4.43 & 4.78 & 0.35 & -4.78 & 32.16 & 34.59 & 29.81 & 1.41
\end{tabular}

The experimental absorption maxima of $6 \mathbf{a}$ were found to be 332 (acetone), 305 (DMSO) and 300 (1,4-dioxane), while the TDDFT absorption maxima were found to be 364, 342, 327 and $302 \mathrm{~nm}$ in the gas phase with major molecular orbital contributions HOMO $\rightarrow$ LUMO (97\%), HOMO $\rightarrow$ LUMO+1 (99\%), $\mathrm{HOMO}+4 \rightarrow$ LUMO (27\%) and HOMO $\rightarrow$ LUMO+1 (52\%), respectively (Table 4). For $\mathbf{6 b}$, the experimental absorption maxima were found to be 377 (acetone), 300 (DMSO) and $373 \mathrm{~nm}$ (1,4-dioxane), while the TD-DFT absorption maxima were found to be $367,336,329$ and $307 \mathrm{~nm}$ in the gas phase with major molecular orbital contributions HOMO $\rightarrow$ LUMO (97\%), HOMO $\rightarrow$ LUMO+1 (98\%), HOMO+4 $\rightarrow$ LUMO (25\%) and HOMO-1 $\rightarrow$ LUMO (60\%), respectively (Table 4). Similarly, for $\mathbf{6 c}$, the experimental absorption maxima were found to be 332 (acetone), 311 (DMSO) and $305 \mathrm{~nm}$ (1,4-dioxane), while the TD-DFT absorption maxima were found to be 367,343 and $328 \mathrm{~nm}$ in the gas phase with major molecular orbital contributions HOMO $\rightarrow$ LUMO (97\%), HOMO $\rightarrow$ LUMO+1 (98\%) and HOMO+4 $\rightarrow$ LUMO (26\%), respectively (Table 4). Further, for $\mathbf{6 d}$, the experimental absorption maxima were found to be 365 (acetone), 313 (DMSO) and $372 \mathrm{~nm}$ (1,4-dioxane), while the TD-DFT absorption maxima were found to be 368, 350 and $327 \mathrm{~nm}$ in the gas phase with major molecular orbital contributions HOMO $\rightarrow$ LUMO (96\%), HOMO $\rightarrow$ LUMO+1 (98\%) and HOMO-1 $\rightarrow$ LUMO (28\%), respectively

Table 4 Wavelengths, excitation energies, and oscillator strengths for $6 a-d^{a}$

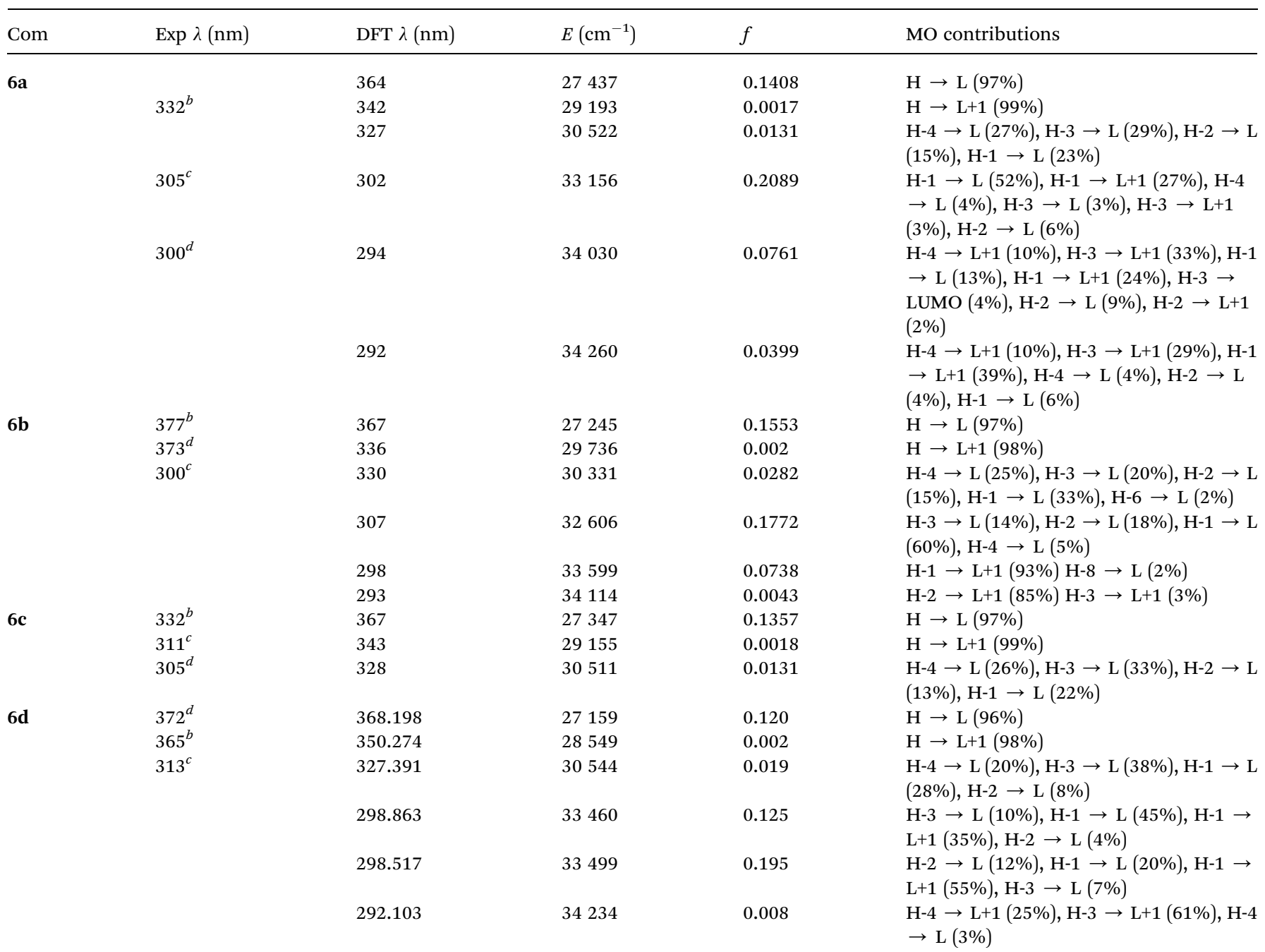

${ }^{a} \mathrm{Com}=$ compounds; Exp $=$ experimental $E=$ Excitation energy $\lambda \lambda=$ wavelength $;=$ oscillator strength $; \mathrm{MO}=$ molecular orbitals; $\mathrm{H}=\mathrm{HOMO} ; \mathrm{L}=$ LUMO; $\lambda(\mathrm{nm}) .{ }^{b}$ Acetone. ${ }^{c}$ DMSO. ${ }^{d} 1,4$-Dioxane. 
(Table 4). The maximum absorption bands of the investigated derivatives (6a-d) are visibly redshifted, which could be because of the conjugated fused ring system and the influence of the substituents. The bands at the maximum wavelengths might be assigned to the $\mathrm{n} \pi^{*}$ transitions of the $\mathrm{C}=\mathrm{C}, \mathrm{C}=\mathrm{N}$ and $\mathrm{C}=\mathrm{O}$ bonds of the investigated derivatives (6a-d) while the bands at lower wavelengths $(\sim 290 \mathrm{~nm})$ might be assigned to the $\pi-\pi^{*}$ transitions of the benzene and pyridine rings (Table 4 ). The UVvisible data reveal good agreement between the experimental and TD-DFT findings.

\section{Nonlinear optical (NLO) properties}

Nonlinear optical (NLO) organic molecules have attracted great industrial, current research and academic interest because of their potential applications in the field of optoelectronic technologies. ${ }^{48}$ The organic second-order nonlinear optical materials have promising applications in the field of nonlinear optics (NLO) owing to their chemical tunability and choice of synthetic strategies. ${ }^{49}$ The sketch of dynamic organic compounds for utilization in NLO response is established on the basis of asymmetric (neocentromeric) polarization. The NLO efficiency could be enhanced by increasing the electron donating and withdrawing groups attached to the $\pi$-conjugated system. Therefore, we also studied NLO parameters of the $\pi$ conjugated systems at the molecular level (6a-d) using the B3LYP level of theory with the $6-311+G(d, p)$ basis set. In the finite field (FF) method, when a species is placed in a static field $(F)$, the resulting energy $(E)$ is represented by eqn (10):

$$
E=E^{0}-\mu_{\mathrm{i}} F_{\mathrm{i}}-\frac{1}{2} \alpha_{\mathrm{ij}} F_{\mathrm{i}} F_{\mathrm{j}} F_{\mathrm{k}}-\frac{1}{24} \gamma_{\mathrm{ijk} \mathrm{l}} F_{\mathrm{i}} F_{\mathrm{j}} F_{\mathrm{k}} F_{1}
$$

where $E_{0}$ stands for the molecular energy in the absence of an electronic field. $\alpha$ represents polarizability, $\beta_{\text {tot }}$ is the first hyperpolarizability, and $\gamma$ stands for the second hyperpolarizability, which are calculated by eqn (11)-(13) from the tensors in the $x, y$ and $z$ directions.

$$
\begin{gathered}
\alpha=1 / 3\left(\alpha_{x x}+\alpha_{y y}+\alpha_{z z}\right) \\
\beta_{\text {tot }}=\left(\beta_{x}{ }^{2}+\beta_{y}{ }^{2}+\beta_{z}{ }^{2}\right)^{1 / 2} \\
\beta_{\text {tot }}=\left[\left(\beta_{x x x}+\beta_{x y y}+\beta_{x z z}\right)^{2}+\left(\beta_{y y y}+\beta_{y z z}+\beta_{y x x}\right)^{2}\right. \\
\left.+\left(\beta_{z z z}+\beta_{z x x}+\beta_{x y z}\right)^{2}\right]^{1 / 2}
\end{gathered}
$$

The first order and the second-order hyperpolarizability for 6a-d, as well as their component values, are summarized in Tables S15 and S16. $\dagger$

The first order polarizability along the $x$ direction was found to be $346,331,355$ and 354 a.u. for $\mathbf{6 a - d}$, respectively. The first order polarizability along the $x$ direction is larger than along the $y$ and $z$ directions (positive directions) for all compounds, which indicates the non-uniform distribution of the charges on the molecules. The total dipole polarizability $\left(\alpha_{\text {total }}\right)$ was found to be 238, 223, 251 and 261 a.u. for 6a-d, respectively (Table S15 $\dagger$ ). The dipole polarizability magnitudes of $\mathbf{6 c}$ and $\mathbf{6 d}$ are approximately the same but greater than those for $\mathbf{6 a}$ and $\mathbf{6 b}$. The first order hyperpolarizability was found to be 1144.46, 1468.42,
1103.06 and 1095.34 a.u. for $\mathbf{6 a - d}$, respectively (Table S16 $†$ ). The first order hyperpolarizability of $\mathbf{6 b}$ is higher than those for $\mathbf{6 a}$, 6c and $\mathbf{6 d}$, which might be due to the electron withdrawing ability because of the more electronegative fluoro group. Moreover, we compared our obtained parameters for $\mathbf{6 a - d}$ with urea because it is frequently used as a reference molecule for comparative NLO analysis. The first order hyperpolarizability for $\mathbf{6 a}-\mathbf{d}$ is remarkably greater than the value for urea $(\beta=43$ a.u.), ${ }^{50}$ which is due to the effect of the extended conjugation in said compounds (Table S16†).

\section{MEP analysis}

The reactive sites of molecules $6 \mathbf{6}-\mathbf{d}$ have been determined by MEP descriptor. The MEP descriptor is more frequently utilized for the affirmation of the molecular domains that are most suitable susceptible towards nucleophilic and electrophilic attacks. ${ }^{51}$ The MEP descriptor is mostly visualized by mapping values on the electron density surface, which is the procedure adopted in our study. MEP surfaces have been displaced in Figure S5. $\dagger$ With respect to the displayed MEP surface of molecules $\mathbf{6 a - d}$, the fluoro, oxygen and nitrogen atoms are considered as sensitive to electrophilic attacks because the MEP surface has the maximal electron density values at these areas. Lower MEP electron density values are situated in the near vicinities of hydrogen atoms and carbon atoms, designating these areas as possibly most sensitive for nucleophilic attacks.

\section{Conclusions}

In summary, we synthesized four novel (hydroxybenzoyl)pyrido $[2,3-d]$ pyrimidine heterocycle derivatives $\mathbf{6 a - d}$ with the chemical formulas of $\mathrm{C}_{16} \mathrm{H}_{13} \mathrm{~N}_{3} \mathrm{O}_{4}, \mathrm{C}_{17} \mathrm{H}_{15} \mathrm{~N}_{3} \mathrm{O}_{4}, \mathrm{C}_{18} \mathrm{H}_{17} \mathrm{~N}_{3} \mathrm{O}_{4}$ and $\mathrm{C}_{15} \mathrm{H}_{10} \mathrm{FN}_{3} \mathrm{O}_{4}$ and good yields of $92 \%$, $77 \%$, 88\%, and $89 \%$, respectively. Their chemical structures have been characterized using experimental and sophisticated computational methods. The experimental techniques of ${ }^{1} \mathrm{H} \mathrm{NMR},{ }^{13} \mathrm{C} \mathrm{NMR}$, UV-vis and FT-IR, as well as SC-XRD, were performed to characterize the synthesized derivatives. SC-XRD analysis revealed that $\mathbf{6 a}-\mathbf{c}$ crystallized in the monoclinic crystal lattice with the $P 2_{1} / n, C 2 / c$ and $P 2_{1} / c$ space groups, respectively, but 6d crystallized in a triclinic crystal lattice with the $P \overline{1}$ space group. Spectroscopic findings were found to be quite in line with the SC-XRD data. Further, the quantum chemical-based UV-vis absorption and FT-IR spectra were also found to be quite in line with the SC-XRD and experimental spectroscopic findings. FMO analysis indicated that the studied derivatives are kinetically stable hard compounds with small electron accepting and greater electron donating capabilities. NBO analysis revealed that the increased stability in $\mathbf{6 a - d}$ is mainly contributed to by strong intramolecular hyper-conjugative interactions. Comparative analysis of the NLO properties revealed that $\mathbf{6 a - d}$ have higher NLO values than urea, making them brilliant candidates for hi-tech applications associated with NLO properties. The MEP surfaces of molecules 6ad revealed that the fluoro, oxygen and nitrogen atoms are considered sensitive to electrophilic attacks. 


\section{Conflicts of interest}

The authors declare that they have no conflicts of interest.

\section{Acknowledgements}

Ataualpa A. C. Braga (grants \# 2011/07895-8, 2015/01491-3 and 2014/25770-6) is thankful to Fundação de Amparo à Pesquisa do Estado de São Paulo for financial support. AACB (grant 309715/ 2017-2) also thanks the Brazilian National Research Council (CNPq) for financial support and fellowships. This study was financed in part by the Coordenação de Aperfeiçoamento de Pessoal de Nível Superior - Brasil (CAPES) - Finance Code 001.

\section{References}

1 M. R. Mohammadizadeh, J. Azizian, F. Teimouri, A. A. Mohammadi, A. R. Karimi and E. Tamari, Can. J. Chem., 2008, 86, 925-929.

2 M. L. Deb and P. J. Bhuyan, Beilstein J. Org. Chem., 2010, 6, 11.

3 A. Shamroukh, A. Rashad and F. Abdelmegeid, J. Chem. Pharm. Res., 2016, 8, 734-772.

4 A. Rajawat, S. Khandelwal and M. Kumar, Green Chem. Lett. Rev., 2014, 7, 37-45.

5 S. R. Klutchko, H. Zhou, R. T. Winters, T. P. Tran, A. J. Bridges, I. W. Althaus, D. M. Amato, W. L. Elliott, P. A. Ellis and M. A. Meade, J. Med. Chem., 2006, 49, 14751485.

6 J. B. Smaill, B. D. Palmer, G. W. Rewcastle, W. A. Denny, D. J. McNamara, E. M. Dobrusin, A. J. Bridges, H. Zhou, H. H. Showalter and R. T. Winters, J. Med. Chem., 1999, 42, 1803-1815.

7 M. R. Reddy, B. Akula, S. C. Cosenza, S. Athuluridivakar, M. R. Mallireddigari, V. R. Pallela, V. K. Billa, D. V. Subbaiah, E. V. Bharathi and R. Vasquez-Del Carpio, J. Med. Chem., 2014, 57, 578-599.

8 N. R. Mohamed, M. M. Abdelhalim, Y. A. Khadrawy, G. A. Elmegeed and O. M. Abdel-Salam, Steroids, 2012, 77, 1469-1476.

9 J. A. Palop, D. Plano, E. Moreno and C. Sanmartín, ARKIVOC, 2014, 2, 187-206.

10 M. M. Gineinah, M. N. Nasr, S. M. Badr and W. M. ElHusseiny, Med. Chem. Res., 2013, 22, 3943-3952.

11 A. Elgohary and E. E.-A. E. Green, Sci. J. Chem., 2013, 1, 1-6. 12 S. A. Rostom, G. S. Hassan and H. I. El-Subbagh, Arch. Pharm., 2009, 342, 584-590.

13 P. Molina, E. Aller, Á. Lorenzo, P. López-Cremades, I. Rioja, A. Ubeda, M. C. Terencio and M. J. Alcaraz, J. Med. Chem., 2001, 44, 1011-1014.

14 A. Y. Kots, B.-K. Choi, M. E. Estrella-Jimenez, C. A. Warren, S. R. Gilbertson, R. L. Guerrant and F. Murad, Proc. Natl. Acad. Sci. U. S. A., 2008, 105, 8440-8445.

15 A. Pastor, R. Alajarin, J. J. Vaquero, J. Alvarez-Builla, M. F. de Casa-Juana, C. Sunkel, J. G. Priego, I. Fonseca and J. SanzAparicio, Tetrahedron, 1994, 50, 8085-8098.
16 Q.-u.-N. Tariq, S. Malik, A. Khan, M. M. Naseer, S. U. Khan, A. Ashraf, M. Ashraf, M. Rafiq, K. Mahmood, M. N. Tahir and Z. Shafiq, Bioorg. Chem., 2019, 84, 372-383.

17 S. Naseem, M. Khalid, M. N. Tahir, M. A. Halim, A. A. C. Braga, M. M. Naseer and Z. Shafiq, J. Mol. Struct., 2017, 1143, 235-244.

18 M. Yaqub, R. Perveen, Z. Shafiq, H. Pervez and M. N. Tahir, Synlett, 2012, 23, 1755-1758.

19 M. Islam, A. Khan, M. T. Shehzad, A. Hameed, N. Ahmed, S. A. Halim, M. Khiat, M. U. Anwar, J. Hussain, R. Csuk, Z. Shafiq and A. Al-Harrasi, Bioorg. Chem., 2019, 87, 155-162.

20 M. T. Shehzad, A. Imran, G. S. S. Njateng, A. Hameed, M. Islam, M. al-Rashida, M. Uroos, A. Asari, Z. Shafiq and J. Iqbal, Bioorg. Chem., 2018, 87, 857-866.

21 E. Taşal, İ. Sıdır, Y. Gülseven, C. Öğretir and T. Önkol, J. Mol. Struct., 2009, 923, 141-152.

22 A. K. Srivastava, A. K. Pandey, S. K. Gangwar and N. Misra, J. At. Mol. Sci., 2014, 5, 279-288.

23 F. Neese, JBIC, J. Biol. Inorg. Chem., 2006, 11, 702-711.

24 M. J. Frisch, G. W. Trucks, H. B. Schlegel, G. E. Scuseria, M. A. Robb, J. R. Cheeseman, G. Scalmani, V. Barone, B. Mennucci, G. A. Petersson, H. Nakatsuji, M. Caricato, X. Li, H. P. Hratchian, A. F. Izmaylov, J. Bloino, G. Zheng, J. L. Sonnenberg, M. Hada, M. Ehara, K. Toyota, R. Fukuda, J. Hasegawa, M. Ishida, T. Nakajima, Y. Honda, O. Kitao, H. Nakai, T. Vreven, J. A. Montgomery Jr, J. E. Peralta, F. Ogliaro, M. Bearpark, J. J. Heyd, E. Brothers, K. N. Kudin, V. N. Staroverov, R. Kobayashi, J. Normand, K. Raghavachari, A. Rendell, J. C. Burant, S. S. Iyengar, J. Tomasi, M. Cossi, N. Rega, J. M. Millam, M. Klene, J. E. Knox, J. B. Cross, V. Bakken, C. Adamo, J. Jaramillo, R. Gomperts, R. E. Stratmann, O. Yazyev, A. J. Austin, R. Cammi, C. Pomelli, J. W. Ochterski, R. L. Martin, K. Morokuma, V. G. Zakrzewski, G. A. Voth, P. Salvador, J. J. Dannenberg, S. Dapprich, A. D. Daniels, Ö. Farkas, J. B. Foresman, J. V. Ortiz, J. Cioslowski and D. J. Fox, Gaussian 09, Gaussian, Inc., Wallingford CT, 2009. 25 M. García-Melchor, A. A. Braga, A. Lledos, G. Ujaque and F. Maseras, Acc. Chem. Res., 2013, 46, 2626-2634.

26 R. Dennington, T. Keith and J. Millam, Gauss View, Version 5 , Semichem Inc., Shawnee Mission, KS, 2009.

27 Avagadro, http://avogadro.cc/wiki/Main_Page.

28 ChemCraft, http://www.chemcraftprog.com.

29 M. Tammer, Colloid Polym. Sci., 2004, 283, 235.

30 R. Lu, W. Gan, B.-h. Wu, Z. Zhang, Y. Guo and H.-f. Wang, J. Phys. Chem. B, 2005, 109, 14118-14129.

31 D. N. Sathiyanarayanan, Vibrational Spectroscopy, New Age International Publishers, New Delhi, 2004, pp. 424-426.

32 E. D. Glendening, J. Badenhoop and F. Weinhold, J. Comput. Chem., 1998, 19, 628-646.

33 J. Foster and F. Weinhold, J. Am. Chem. Soc., 1980, 102, 72117218.

34 A. E. Reed and F. Weinhold, J. Chem. Phys., 1983, 78, 40664073.

35 A. E. Reed, R. B. Weinstock and F. Weinhold, J. Chem. Phys., 1985, 83, 735-746. 
36 J. E. Carpenter, Extension of Lewis structure concepts to openshell and excited-state molecular species, University of Wisconsin-Madison, 1987.

37 J. Carpenter and F. Weinhold, J. Mol. Struct.: THEOCHEM, 1988, 169, 41-62.

38 A. E. Reed, L. A. Curtiss and F. Weinhold, Chem. Rev., 1988, 88, 899-926.

39 F. Weinhold and C. R. Landis, Chem. Educ. Res. Pract., 2001, 2, 91-104.

40 M. Shahid, M. Salim, M. Khalid, M. N. Tahir, M. U. Khan and A. A. C. Braga, J. Mol. Struct., 2018, 1161, 66-75.

41 M. Adeel, A. A. Braga, M. N. Tahir, F. Haq, M. Khalid and M. A. Halim, J. Mol. Struct., 2017, 1131, 136-148.

42 M. Srnec and E. I. Solomon, J. Am. Chem. Soc., 2017, 139, 2396-2407.

43 F. Kandemirli and S. Sagdinc, Corros. Sci., 2007, 49, 21182130.
44 R. G. Parr, L. v. Szentpály and S. Liu, J. Am. Chem. Soc., 1999, 121, 1922-1924.

45 R. G. Parr, R. A. Donnelly, M. Levy and W. E. Palke, J. Chem. Phys., 1978, 68, 3801-3807.

46 P. K. Chattaraj, U. Sarkar and D. R. Roy, Chem. Rev., 2006, 106, 2065-2091.

47 A. Lesar and I. Milošev, Chem. Phys. Lett., 2009, 483, 198-203.

48 M. U. Khan, M. Khalid, M. Ibrahim, A. A. C. Braga, M. Safdar, A. A. Al-Saadi and M. R. S. A. Janjua, J. Phys. Chem. C, 2018, 122, 4009-4018.

49 M. U. Khan, M. Ibrahim, M. Khalid, M. S. Qureshi, T. Gulzar, K. M. Zia, A. A. Al-Saadi and M. R. S. A. Janjua, Chem. Phys. Lett., 2019, 715, 222-230.

50 C. Qin and A. E. Clark, Chem. Phys. Lett., 2007, 438, 26-30. 51 I. Javed, A. Khurshid, M. N. Arshad and Y. Wang, New J. Chem., 2014, 38, 752-761. 